\title{
Facial alveolar bone thickness and modifying factors of anterior maxillary teeth: a systematic review and meta-analysis of cone-beam computed tomography studies
}

Julio Rojo-Sanchis $(\mathbb{D}$, David Soto-Peñaloza@, David Peñarrocha-Oltra®, Miguel Peñarrocha-Diago® and José Viña-Almunia* (i)

\begin{abstract}
Background: Understanding the anatomy of the facial alveolar bone (FAB), provides a prognostic tool for estimating the degree of dimensional ridge alterations after tooth extraction. This systematic review and meta-analysis aims to determine the FAB thickness and modifying factors of anterior maxillary teeth measured by CBCT scans. A secondary objective was to assess the facial distance from the cementoenamel junction (CEJ) to the bone crest.

Methods: An electronic search was made of Medline, Embase, Web of Science, Cochrane Library and Google Scholar up to December 2019. Studies that analyze and quantitatively compare FAB thickness at maxillary teeth by CBCT scans were included. The methodological quality of the included studies was appraised using the ROBINS-I tool and the overall meta-evidence certainty using the GRADE approach. A single means random-effects meta-analysis was performed to obtain the weighted mean for $95 \%$ confidence interval. A meta-regression of covariates and subgroup analysis was conducted. The nullity $\mathrm{Q}_{\mathrm{h}}$ test and $\mathrm{I}^{2}$ index for heterogeneity was estimated.

Results: 2560 potentially relevant articles were recorded from which 29 studies were selected for the qualitative analysis, including 17,321 teeth. Seventeen studies considered the facial bone crest, and 12 the CEJ as a reference point for their measurements. Mean FAB thickness was $\leq 1 \mathrm{~mm}$ in maxillary incisors and canines $(0.75-1.05 \mathrm{~mm})$ and 1-2 $\mathrm{mm}$ in premolars. Patients over 50 years of age, females and thin gingival phenotype was associated with thinner FAB at some apico-coronal locations of maxillary incisors and canines. The geographical setting was an effect modifier that could explain up to $87 \%$ of the heterogeneity in FAB thickness, being Asian populations that showed the lowest FAB thickness values. The CEJ-bone crest distance was $2-2.5 \mathrm{~mm}$ in all teeth analyzed. Population over 50 years of age exhibited greater CEJ-bone crest distances, and males also showed a trend for greater distance. Evidence certainty has shown moderate quality in most analysis subsets.
\end{abstract}

Conclusions: Facial alveolar bone at anterior maxillary teeth is thin, heterogeneous in width along its apico-coronal dimensions, and increases in thickness in maxillary premolars. The CEJ-bone crest distance presented homogeneous and similar values in all teeth analyzed.

Keywords: Buccal bone, Facial alveolar bone, Cone-beam computed tomography, CEJ, Maxillary teeth, Meta-analysis

*Correspondence: jose-a.vina@uv.es

Oral Surgery Unit, Department of Stomatology, Faculty of Medicine

and Dentistry, University of Valencia, Gascó Oliag 1, Valencia 46010, Spain

(C) The Author(s) 2021. Open Access This article is licensed under a Creative Commons Attribution 4.0 International License, which permits use, sharing, adaptation, distribution and reproduction in any medium or format, as long as you give appropriate credit to the original author(s) and the source, provide a link to the Creative Commons licence, and indicate if changes were made. The images or other third party material in this article are included in the article's Creative Commons licence, unless indicated otherwise in a credit line to the material. If material is not included in the article's Creative Commons licence and your intended use is not permitted by statutory regulation or exceeds the permitted use, you will need to obtain permission directly from the copyright holder. To view a copy of this licence, visit http://creativecommons.org/licenses/by/4.0/. The Creative Commons Public Domain Dedication waiver (http://creativeco mmons.org/publicdomain/zero/1.0/) applies to the data made available in this article, unless otherwise stated in a credit line to the data. 


\section{Background}

In a large percentage of cases, the anterior maxillary region exhibits very thin facial alveolar bone (FAB), which is often made up only of bundle bone [1]. It is considered to be part of the periodontium, and is coupled to the existence of a tooth root and a periodontal ligament; as a result, it is reabsorbed after tooth extraction [2].

Understanding the anatomy of the alveolar ridges and FAB thickness provides the clinician with a prognostic tool for estimating the degree of future bone loss after tooth extraction [3]. After exodontia, variable amounts of bone resorption occur secondary to qualitative and quantitative changes at the edentulous site of the alveolar process $[4,5]$. It is also well known that bone resorption will be greater at the buccal aspect than at the lingual/palatal aspect [2], and that the healthy neighboring dentition maintains bone resorption in proximal areas $[6,7]$. The thickness of the FAB is of utmost relevance in the morphological changes of the postextraction alveolus [8]. In this regard, it has been demonstrated that when the thickness is $<1 \mathrm{~mm}$, a mean loss in the height of $7.5 \mathrm{~mm}$ occurs after single tooth extraction, while in the cases of thickness $\geq 1 \mathrm{~mm}$, the mean loss in height is $1.1 \mathrm{~mm}$ [9]. Moreover, some authors decide the timing of implant placement after single tooth extraction according to FAB thickness [10]. There is currently no consensus regarding the minimal FAB thickness required to avoid ridge resorption [11].

The effect of systemic diseases, occlusal relationship and smoking habits on FAB thickness have been evaluated, but none of these factors has demonstrated a significant influence on FAB anatomy [12]. Zhang et al. [13] in a case-control study showed that postmenopausal women exhibited thinner FAB than premenopausal women and older men. Thus, according to this study, patient hormonal status could influence the facial bone thickness. Some recent studies [14-16] have observed a reduced FAB thickness in individuals aged 50 years or older; patient age therefore also seems to influence FAB thickness.

It has not been determined whether FAB thickness increases or decreases from coronal to apical areas. While some authors have reported an increase in thickness from coronal to apical levels [17-19], others [20, 21] have obtained opposite results, i.e., thicker FAB at the coronal crest. In recent years, several authors [22-25] have studied and analyzed FAB thickness, though much uncertainty remains regarding the different patterns of FAB thickness and the factors that can influence them.

To our knowledge, no previous systematic review has investigated the anatomy of FAB at maxillary teeth. The present systematic review was therefore carried out to critically and comprehensively analyze the FAB thickness of anterior maxillary teeth measured by cone-beam computed tomography (CBCT) scans. A secondary aim was to assess the distance from the cementoenamel junction (CEJ) to the facial bone crest (FBC).

\section{Methods}

This systematic review was conducted following the Preferred Reporting Items for Systematic Reviews and Meta-analyses (PRISMA) [26]. The review was prospectively developed and registered in the PROSPERO database of the University of York, with protocol number: CRD42019120631.

\section{Focused question}

Two a priori defined focused questions based on the participant $(\mathrm{P})$, exposure $(\mathrm{E})$ and outcome $(\mathrm{O})$ format were formulated:

Q1: What is the facial alveolar bone thickness at anterior maxillary teeth measured with cone-beam computer tomography scans?

Q2: What is the CEJ-facial bone crest distance at anterior maxillary teeth measured with cone-beam computer tomography scans?

- Population: Patients with anterior maxillary teeth (from second to the second premolar).

- Exposure: Cone-beam computed tomography scan.

- Outcomes: (i) Facial alveolar bone (FAB) thickness at different apico-coronal levels, measured from facial bone crest $(\mathrm{FBC})$ or CEJ. (ii) The distance from facial bone crest $(\mathrm{FBC})$ to the $\mathrm{CEJ}$.

\section{Information sources and electronic searching}

Two independent reviewers performed an electronic and manual search (JRS and DSP) consulting four main databases and Google Scholar up to December 2019: Medline via PubMed, Web of Science, Embase and Cochrane Library and gray literature. The search strategy combined "MESH" medical subject headings (PubMed) and EMTREE (EMBASE) indexed terms and other free-text terms were combined whenever possible to lessen the risk for selection bias. On a complementary basis, primary source journals related to the study topic were consulted manually covering the last two years. The really syndication service (RSS) feed for PubMed was employed to identify and retrieve new indexed titles fitted to the search strategy. Finally, the 
reference lists of included studies were consulted to retrieve potential eligible titles, as suggested by Greenhalgh and Peacock [27]. No restrictions were imposed regarding language or date of publication. Discrepancies of retrieved titles were resolved by discussion with a third advisor (J.V.A.). The search strategies tailored for each database are depicted in Table 1.

\section{Eligibility criteria}

Studies were selected according to the following eligibility criteria:

- Inclusion criteria: observational clinical studies (e.g., retrospective cohort, cross-sectional, casecontrol studied) and randomized controlled tri-

Table 1 Search strategies used for each database, with the corresponding results covering the period up to December 2019

\begin{tabular}{|c|c|c|c|}
\hline \multicolumn{4}{|c|}{ Main databases } \\
\hline Database & Search strategy employed & Limits & Dec 24, 2019 \\
\hline Pubmed & $\begin{array}{l}\text { (((((“"Bicuspid"[Mesh] OR "Tooth"[Mesh] OR "Cuspid"[Mesh] OR premolar OR incisor OR canine OR second pre- } \\
\text { molar OR first premolar OR lateral incisor))) NOT ((“Molar"[Mesh] OR"Root Canal Therapy"[Mesh] OR"Root } \\
\text { Canal Preparation"[Mesh] OR"Root Canal Obturation"[Mesh] OR impacted canines OR impacted tooth } \\
\text { OR"Tooth, Nonvital"[Mesh] OR“Dental Implants, Single-Tooth"[Mesh])))) AND ("Cone-Beam Computed } \\
\text { Tomography"[Mesh] OR CBCT OR cone beam volume CT OR cone beam CT OR cone-beam CT)) AND } \\
\text { (((CEJ OR cement enamel junction OR vestibular bone peak OR facial bone crest) OR (facial alveolar bone } \\
\text { width OR buccal bone thickness OR buccal cortical OR facial bone OR socket bony walls OR facial bone } \\
\text { wall OR buccal alveolar bone))) }\end{array}$ & All text & 757 \\
\hline EMBASE & $\begin{array}{l}\text { ('bicuspid'/exp OR 'bicuspid' OR 'tooth'/exp OR 'tooth' OR 'cuspid'/exp OR 'cuspid' OR'premolar tooth'/exp OR } \\
\text { 'premolar tooth' OR'incisive' OR'canine tooth'/exp OR 'canine tooth' OR 'second premolar'/exp OR 'second } \\
\text { premolar'OR 'first premolar'/exp OR 'first premolar' OR'lateral incisive') AND ('computer tomography'/exp } \\
\text { OR'computer tomography') OR'cbct' OR'cone beam' OR'cone-beam'OR'cone beam computer tomogra- } \\
\text { phy') AND ('cementoenamel junction' OR cej OR 'buccal bone crest' OR'facial bone'/exp OR'facial bone' OR } \\
\text { 'facial alveolar bone width' OR 'facial alveolar bone' OR'facial alveolar' OR'buccal bone thickness' OR 'buccal } \\
\text { bone' OR'buccal cortical' OR 'socket bone wall' OR'facial bone wall') }\end{array}$ & All text & 733 \\
\hline COCHRANE & $\begin{array}{l}\text { "bicuspid" OR "cuspid" OR Incisor OR "Tooth" OR premolar tooth OR Incisive OR incisive tooth OR second } \\
\text { premolar OR lateral incisive in Title Abstract Keyword AND "Cone Beam Computed Tomography" or "Cone } \\
\text { Beam Computer Assisted Tomography" or "Cone Beam Computerized Tomography" or "Cone Beam CT" } \\
\text { or "Volumetric Computed Tomography" or "Volumetric CT" or "Cone-Beam Computed Tomography" or } \\
\text { "Cone-Beam Computer-Assisted Tomography" or "Cone-Beam Computerized Tomography" or "Cone-Beam } \\
\text { CT" or "Cone-Beam CT Scan" in Title Abstract Keyword AND "cement enamel junction" OR CEJ OR Vestibular } \\
\text { bone peak OR "facial bone" OR "Cortical Bone" OR Facial alveolar bone width OR buccal bone OR facial } \\
\text { alveolar bone wall OR buccal alveolar bone OR buccal bone thickness OR buccal cortical OR facial bone OR } \\
\text { facial bone wall in Title Abstract Keyword NOT "root canal therapy" OR "root canal-therapy" OR"root canal } \\
\text { obturation" OR "root canal preparation" OR impacted canine OR"impacted tooth" OR"Impacted Teeth" OR } \\
\text { "tooth non-vital" OR "Dental Implants, Single Tooth" OR "Dental implant" in Title Abstract Keyword-(Word } \\
\text { variations have been searched) }\end{array}$ & All text & 65 \\
\hline \multirow[t]{6}{*}{ WOS } & $\begin{array}{l}\# 1 \mathrm{TS}=\text { (bicuspid) } \mathrm{ORTS}=(\text { cuspid }) \mathrm{ORTS}=\text { (tooth) } \mathrm{ORTS}=\text { (premolar) } \mathrm{ORTS}=\text { (incisor) } \mathrm{ORTS}=\text { (canine) } \mathrm{OR} \\
\mathrm{TS}=\text { (first premolar) } \mathrm{ORTS}=\text { (second premolar) ORTS }=\text { (lateral incisor) }\end{array}$ & All text & 858 \\
\hline & $\begin{array}{l}\# 2 \mathrm{TS}=(\text { computed tomography }) \mathrm{ORTS}=(\mathrm{CBCT}) \mathrm{ORTS}=(\text { cone beam }) \mathrm{ORTS}=(\text { cone-beam }) \mathrm{ORTS}=(\text { cone } \\
\text { beam computer tomography) }\end{array}$ & & \\
\hline & $\begin{array}{l}\text { \#3 TS }=\text { (cement enamel junction OR CEJ) ORTS }=\text { (facial bone crest OR vestibular bone peak) ORTS = (facial } \\
\text { bone) ORTS = (facial alveolar bone width) ORTS = (facial alveolar bone) ORTS = (facial alveolar) OR } \\
\text { TS = (buccal bone thickness) ORTS = (buccal bone) ORTS = (buccal cortical) ORTS= (socket bone wall) OR } \\
\text { TS = (facial bone wall) }\end{array}$ & & \\
\hline & \#4 \#1 AND \#2 AND \#3 & & \\
\hline & $\begin{array}{l}\text { \#5 TS }=\text { (root canal therapy OR root canal-therapy OR root canal obturation OR root canal preparation) OR } \\
\text { TS }=\text { (impacted canine) ORTS = (impacted tooth) ORTS = (Impacted Teeth) OR TS = (tooth non-vital) OR } \\
\text { TS = (Dental Implants, Single Tooth) ORTS }=\text { (Dental implant) }\end{array}$ & & \\
\hline & \#6 \#4 NOT \#5 & & \\
\hline \multirow[t]{4}{*}{ Scholar } & $\begin{array}{l}\text { (Premolar OR incisor OR canine OR second premolar OR first premolar OR lateral incisor) AND ("Cone-Beam } \\
\text { Computed Tomography"[Mesh] OR CBCT) AND (Cement enamel junction OR CEJ OR Facial bone crest OR } \\
\text { facial alveolar bone OR buccal bone) }\end{array}$ & & 147 \\
\hline & & Total & 2560 \\
\hline & & Duplicates & 557 \\
\hline & & $\begin{array}{l}\text { After } \\
\text { duplicates } \\
\text { removal }\end{array}$ & 2003 \\
\hline
\end{tabular}


als if any, that analyze and quantitatively compare FAB thickness at anterior maxillary teeth (incisors, canines and premolars), using CEJ or FBC as a tomographic anatomical reference point.

- Exclusion criteria: articles investigating FAB only with calipers, or computed tomography scans limited to mandibular or posterior maxillary teeth; studies presenting a sample size of $<30$ patients (as a threshold according to central limit theorem for samples with a normal distribution), included patients with dental absences at the anterior maxillary teeth or included patients under 18 years; studies that included patients under orthodontic treatment, bone augmentation procedures, systemic diseases affecting bone metabolism, case reports, case series, abstracts, interviews, editorials and expert opinions.

\section{Study selection}

The titles and abstracts were screened in duplicate (JRS and DSP) using a predefined Excel spreadsheet (Excel for Mac ver. 16.16.2, Microsoft ${ }^{\circledR}$, Redmond, WA, USA). In a second stage, the full-text files of potentially eligible titles were reviewed for definitive inclusion. Eligibility agreement between reviewers was assessed through kappa scores (Cohen's $\mathrm{k}$ coefficient) and interpreted using the Landis and Koch scale. Disagreements were resolved by discussion with a third advisor (J.V.A.).

\section{Study outcomes and evaluation}

Study data were extracted by duplicate (JRS and DSP) seeking comparability in predefined Excel spreadsheets (Excel for Mac ver. 16.16.2, Microsoft ${ }^{\circledR}$, Redmond, WA, USA). The following items were considered: author/year, country, sample size, study design, study quality, age, sex, teeth analyzed, CBCT purpose, presence of dehiscence or fenestration, CBCT general setting, FAB thickness and CEJ-FBC distance. The main objectives of the present study were:

- (i) Primary outcome: FAB thickness at different apicocoronal levels, measured from FBC or CEJ, expressed in $\mathrm{mm}$.

- (ii) Secondary outcome: The distance from the CEJ to the FBC, expressed in $\mathrm{mm}$.

These outcomes were assessed using different anatomical landmarks (Fig. 1):

- Cementoenamel junction (CEJ): The anatomical limit between the anatomical crown and root surface, defined as the junction zone of the cementum and enamel in the cervical region of the tooth [28].

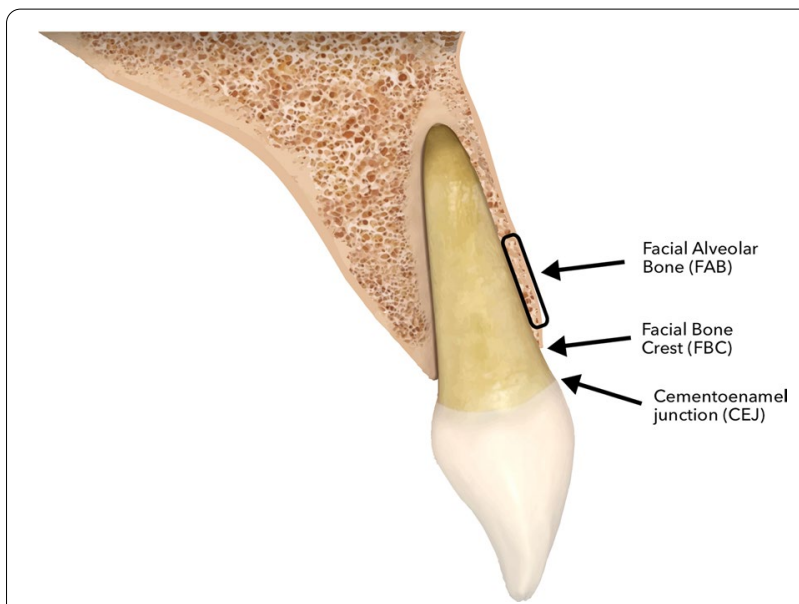

Fig. 1 Location of anatomical landmarks: facial alveolar bone (FAB), facial bone crest (FBC) and cementoenamel junction (CEJ)

- Facial bone crest (FBC): The highest coronal point of facial alveolar bone at the central site of the tooth [29].

\section{Risk of bias of individual studies}

Quality assessment was performed in duplicate by two independent reviewers (J.R.S. and D.S.P.). The ROBINS-I tool from the Cochrane Collaboration was used for nonrandomized studies of interventions (NRSI) [30]. The tool comprises seven items related to preintervention (confounding and selection bias), intervention (classification bias) and post-intervention stages (reporting bias). The studies were judged to have a low risk (low risk of bias for all domains), moderate risk (low or moderate risk of bias for all domains), serious risk (serious risk of bias in at least one domain, but not a critical risk of bias in any domain), critical risk (critical risk of bias in at least one domain) or no information (no clear indication that the study is at serious or critical risk of bias and there is a lack of information in one or more key domains of bias).

\section{Quantitative synthesis and meta-analysis}

Quantitative data were summarized in predefined Excel spreadsheets, seeking comparability between studies. The single mean and standard deviation (mean \pm SD) of FAB thickness at the different apico-coronal levels were estimated, and the distance from CEJ to FBC at the different teeth of the anterior maxilla was also calculated to explore potential interactions with the FAB values. Concerning the primary study objective, the strategy was to segment the data into two groups according to the reference point employed to measure the thickness of FAB: CEJ or FBC. 
If a study failed to provide enough data to estimate the mean and $\mathrm{SD}$ of the FAB values, an e-mail was sent to the corresponding author requesting raw data. A meta-analysis of single means was performed. The $\mathrm{I}^{2}$ index of heterogeneity and the corresponding nullity statistical Q-test was calculated- $\mathrm{I}^{2}$ values of $25 \%, 50 \%$ and $75 \%$ being interpreted as indicating low, moderate and high heterogeneity, respectively. The consistency of results was explored through Galbraith plots. Publication bias was investigated by visual detection on the funnel plot and employing the Egger's test if possible ( $\geq 10$ studies) [31]. A subgroup analysis was designed to assess the effect of age, sex and gingival phenotype.

\section{Additional analyses}

In the case of high heterogeneity, a mixed-effects model meta-regression analysis was performed to detect the effect of potential effect modifiers upon analysis consistency. The impact on heterogeneity being represented by the R-square statistic [32]. A level of significance of $5 \%(\alpha=0.05)$ was established. The $R$ 3.5.1 package ( $\mathrm{R}$ Foundation for Statistical Computing, Vienna, Austria), was employed to perform the present meta-analysis.

The following variables are considered: geographic setting, propensity for confounding- and selection-bias (moderate to serious concerns), periodontal disease, smoking and voxel size resolution.

- Periodontal disease: If the inclusion criteria of primary studies disclose explicitly for no periodontal disease or refer to physiologic bone loss levels accepted as healthy periodontium $(1.0-3.0 \mathrm{~mm})$ from CEJ [33].

- Smoking: The tobacco consumption increases the risk of osteoporosis [34] and has a deleterious effect in periodontal health status [35].

- Voxel size resolution: A voxel size of 0.3 to $0.4 \mathrm{~mm}$ is acceptable for diagnostic quality for implant treatment planning [36].

\section{Evidence certainty}

The GRADE approach using the GRADEpro|GDT software (https://gdt.gradepro.org/app/) was used to assess the overall quality of meta-evidence, according to its level of certainty: very low, low, moderate, or high according to the GRADE handbook (https://gdt.gradepro.org/ app/handbook/handbook.html). The following items are incorporated in summary of findings tables (SoF): risk of bias, inconsistency, indirectness, imprecision and other reasons. This approach is based on the metric scale provided by the ROBINS-I tool for risk of bias. Because included studies are observational, these begin the assessment with a certainty reduction by two levels.

To assess evidence by imprecision, in a first instance, the $95 \% \mathrm{CI}$ is inspected to ascertain that not includes/ crossing the zero value (null effect). If the confidence interval tends toward a side (positive or negative) a maximum error measurement of about $\pm 0.20 \mathrm{~mm}$ is established as a threshold for measurement accuracy (as showed in SoF). Meta-analytic standard deviations surpassing in a tenth, the error point, are considered imprecise.

\section{Results \\ Study selection}

A total of 2560 potentially relevant articles were found through sensitive searches (Fig. 2). After the removal of duplicates, a total of 2003 titles and abstracts were considered to be potentially eligible. Two reviewers (J.R.S. and D.S.P.) were calibrated in the application of the inclusion and exclusion criteria. In the second phase, 64 articles were obtained and assessed by reading the full text. For the systematic review, 29 articles fulfilled the inclusion criteria. The reviewers showed almost perfect agreement $(\mathrm{k}=0.83)$. Discussion with a third advisor (J.V.A.) solved discrepancies between the two reviewers. The reasons for study exclusion after full-text appraisal were recorded (Additional file 1).

\section{Study characteristics}

The 29 included studies were published between 2010 and 2019, with the majority being published in the last five years (Additional file 2). Three included studies were retrospective cohort studies, two were case-control studies, and 24 had a cross-sectional design. All of them measured FAB thickness with $\mathrm{CBCT}$ performed previously for diagnostic purposes. Most studies were moderate to high in terms of sample size (median of 120 patients per study) and 19 analyzed more than 300 teeth. The 29 included studies comprised 3556 patients and measured 17,321 teeth, including maxillary central incisors $(\mathrm{CI})$, lateral incisors $(\mathrm{LI})$, canines $(\mathrm{C})$, first premolars (1PM) and second premolars (2PM). According to the geographical setting of the study sample, 15 studies were made in populations from Asia, five from America, six from Europe and three from Africa. Sixteen studies [12-17, 19, 23, 24, 37-43] analyzed FAB thickness considering $\mathrm{FBC}$ as the anatomical reference point, while 13 studies [20, 22, 25, 44-53] used CEJ. Fifteen studies analyzed the CEJ-FBC distance; ten studies evaluated the prevalence of FAB thickness $<1 \mathrm{~mm}$, and only 7 analyzed the presence of dehiscence or fenestration. 


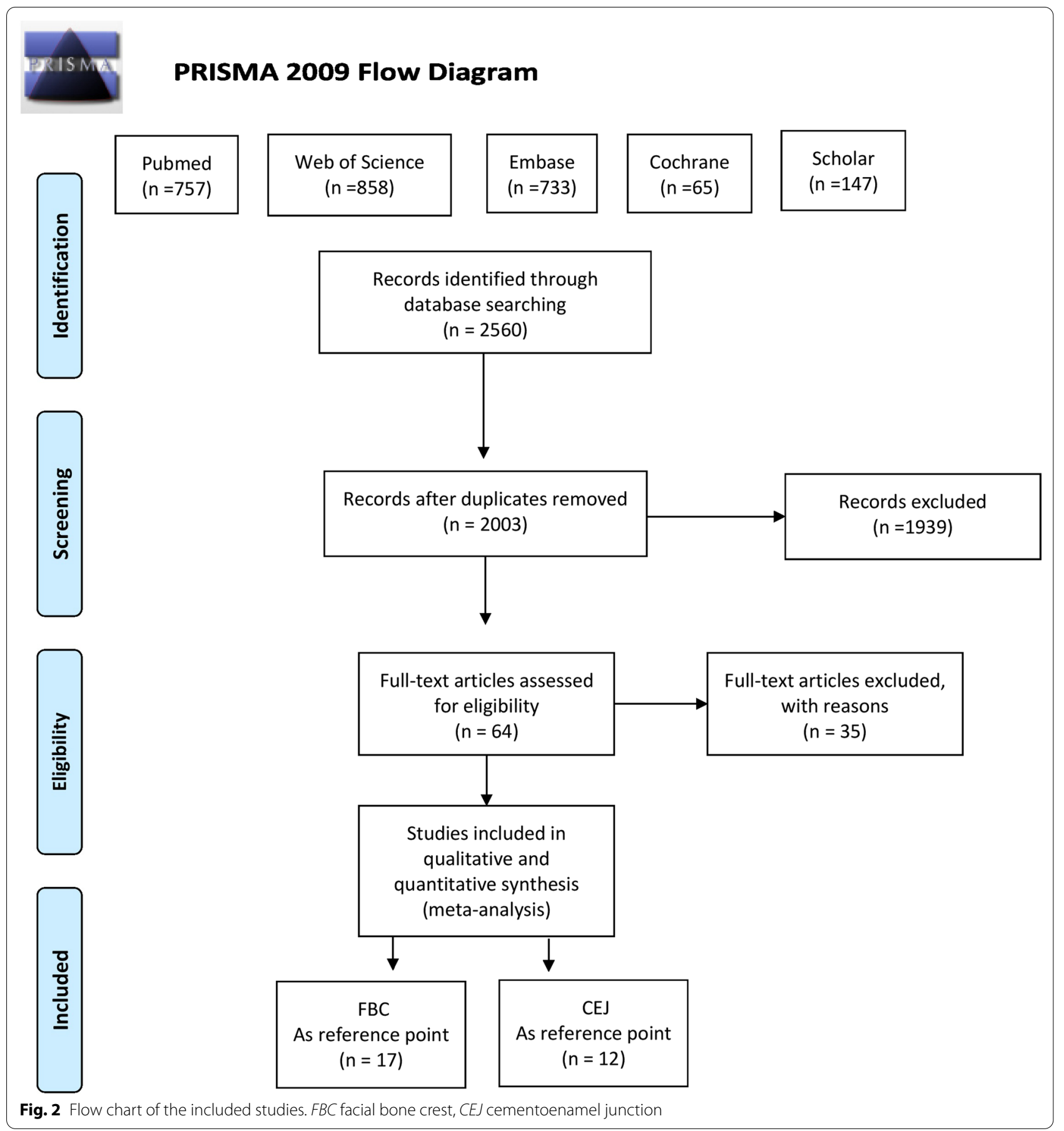

\section{Risk of bias of individual studies}

Assessment of the risk of bias of the included studies with the ROBINS - I tool, showed that only three studies to have a high risk of bias (10.34\%) while the majority of the studies $(n=26 ; 89.65 \%)$ presented a moderate risk of bias (Fig. 3). The most problematic domains were referred to confounding factors (serious in $6.89 \%$ of the studies) and in the selection of participants in the study (serious in $10.34 \%$ of the studies). Low risk of bias was reported for the classification of interventions, due to deviations from intended interventions, missing data, measurements of outcomes and for selection of the reported results in the majority of the studies. Only 1 study [22], performs a priori power calculation. 
ROBINS-I tool Summary of risk of bias among included studies

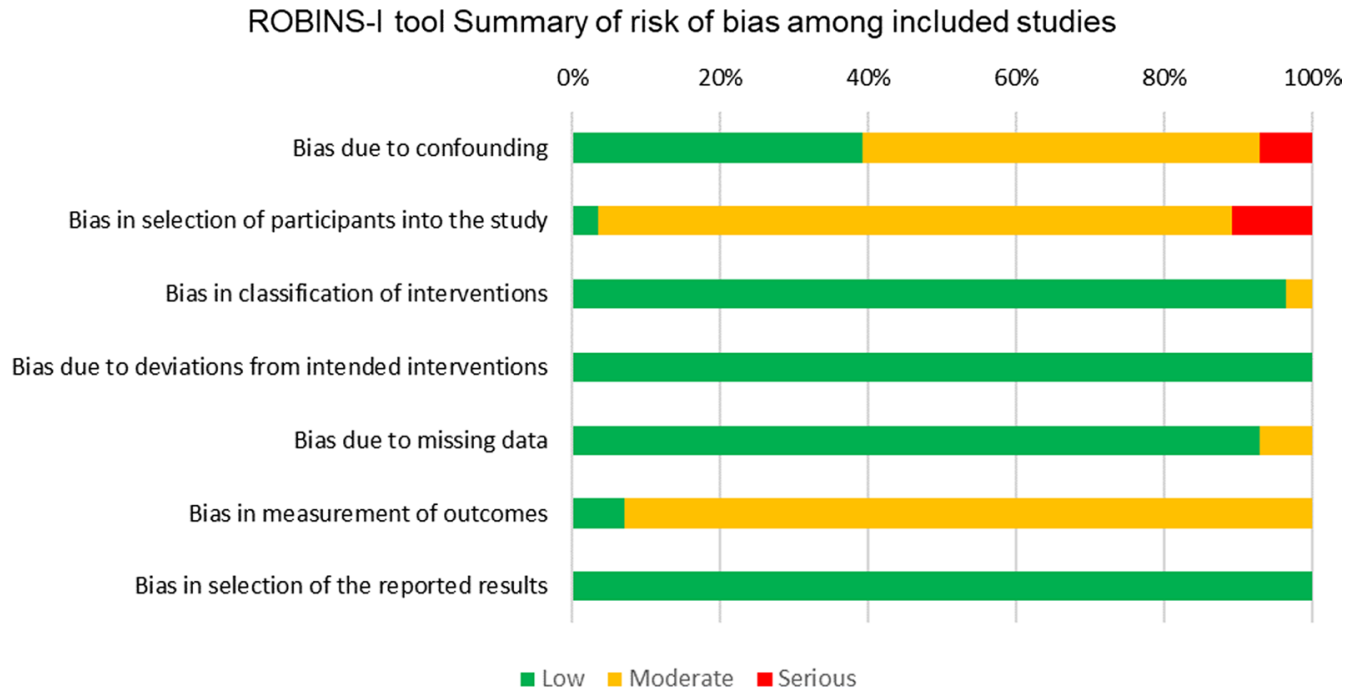

Fig. 3 Risk of bias of individual studies analyzed by the ROBINS-I tool. Four studies showed a high risk of bias (10.34\%), while the majority ( $\mathrm{n}=26$; 86.95\%) showed a moderate risk of bias

\section{Quantitative synthesis of the results}

The thickness of FAB was the main outcome of the present review. However, the different anatomical reference points among the studies were the major limitation establishing comparisons. Data from studies in which FBC was the reference point considered for measurement were analyzed independently from studies that deem CEJ as the anatomical reference point (Fig. 4). The sample of each included study was divided into different age groups to evaluate the influence of age on FAB thickness. However, most of the articles had groups over and under 50 years, so this age was used to compare them.

\section{FAB thickness considering FBC as the anatomical reference point}

Seventeen studies (9264 teeth) used FBC as a reference point. The measurements on which most of the articles agreed were at 1,3 and $5 \mathrm{~mm}$ from FBC. FAB was thicker as the analyzed tooth was located in a more posterior area (Table 2). Mean thickness values at anterior teeth (CI, LI and $\mathrm{C}$ ) were $\leq 1 \mathrm{~mm}(0.75-1.05)$. At maxillary premolars (1PM and 2PM) mean FAB thickness was $>1 \mathrm{~mm}$ (1.091.96). In all teeth analyzed, mean thicker $F A B$ was found at $3 \mathrm{~mm}$ when compared with the measurements at 1 and $5 \mathrm{~mm}$ from the FBC. These findings are observed in a high heterogeneity context.

Sub-group analyses were conducted by age and gender. The analysis by age groups showed that at $5 \mathrm{~mm}$ from $\mathrm{FBC}$, significantly thinner FAB was observed in $>50$ years groups for $C I$ and $C(p<0.05)$. About gender, significantly thicker $F A B$ in males was found at $1 \mathrm{~mm}$ from the $\mathrm{FBC}$ in $\mathrm{LI}$ and $\mathrm{C}(\mathrm{p}<0.05)$, and at $5 \mathrm{~mm}$ from $\mathrm{FBC}$ in $\mathrm{CI}$ $(\mathrm{p}=0.034)$ (Fig. 5). No statistically significant differences were found referred to the other teeth and sites of measurement for age and sex (Additional file 3).

\section{FAB thickness considering CEJ as the anatomical reference point}

Twelve studies (8057 teeth) used CEJ as the anatomical reference point. The measurement locations on which most of the articles agreed were at 4 and $6 \mathrm{~mm}$ from CEJ and at the middle root level.

The mean FAB thickness values were $<1 \mathrm{~mm}$ in all anterior teeth at all measurement locations (0.65-0.9); also, thicker mean values were found at $6 \mathrm{~mm}$ from the CEJ. At maxillary premolars, the mean FAB thickness was $>1 \mathrm{~mm}$, except for $1 \mathrm{PM}$ at the middle root (Table 2). These findings were observed in a high heterogeneity context.

Three studies [44, 45, 49] evaluated the influence of gingival phenotype in FAB thickness at CI, LI and C. Significantly thicker FAB was reported at thick gingival phenotype in all anterior teeth and measurement locations $(\mathrm{p}<0.05)$.

\section{Prevalence of $<1 \mathrm{~mm}$ and $<0.5 \mathrm{~mm}$ FAB}

Ten studies (5516 teeth) evaluated the prevalence of a FAB thickness of less than $1 \mathrm{~mm}$ and $0.5 \mathrm{~mm}$. The prevalence of $<1 \mathrm{~mm}$ FAB thickness was $69.9 \%$ in CI, $64.5 \%$ in LI, $55 \%$ in $\mathrm{C}$ and $40.4 \%$ at $1 \mathrm{PM}$; while the prevalence of $<0.5 \mathrm{~mm}$ was $30.2 \%$ in CI and $35.4 \%$ in LI. There were not enough data to evaluate these prevalences at $2 \mathrm{PM}$ either the percentage of $<0.5 \mathrm{~mm}$ FAB thickness in $\mathrm{C}$ and 1PM. 
FBC

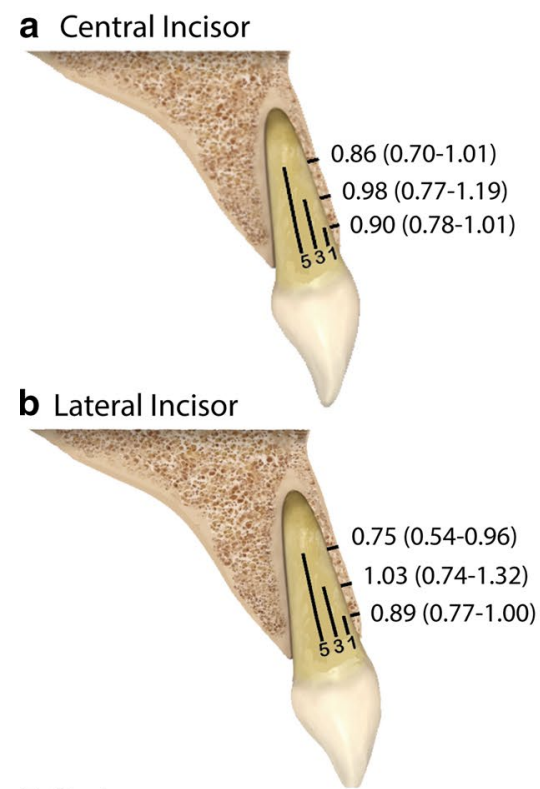

C Canine

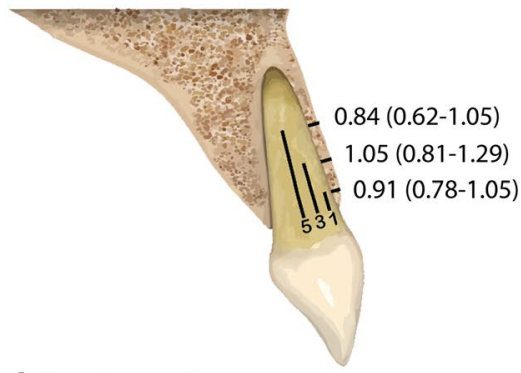

d First Premolar

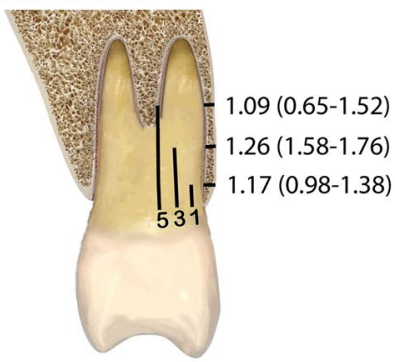

e Second Premolar



CEJ

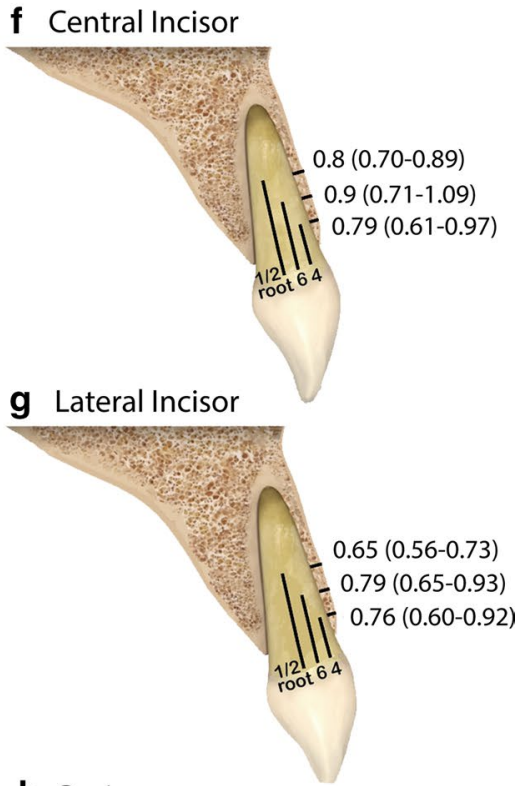

h Canine

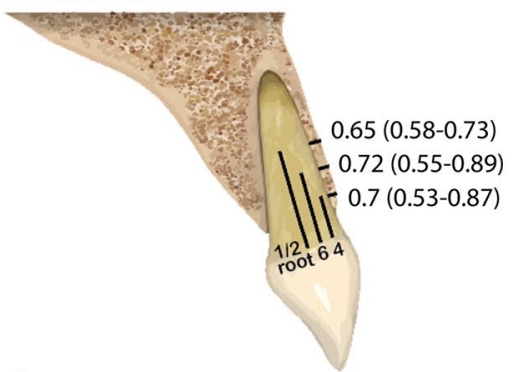

i First Premolar

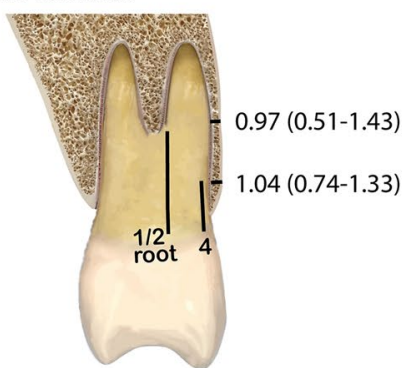

\section{j Second Premolar}

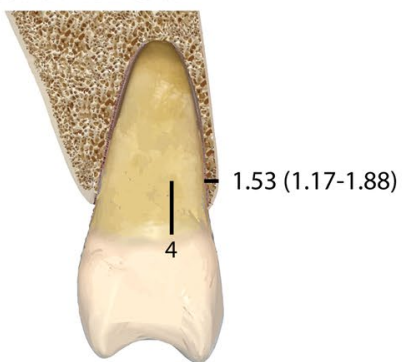

Fig. 4 Facial alveolar bone thickness mean values and ranges expressed in $\mathrm{mm}$. The anterior maxillary teeth measured are represented in the following figures: $\mathbf{a}, \mathbf{f} \mathrm{Cl} ; \mathbf{b}, \mathbf{g} \mathrm{LI} ; \mathbf{c}, \mathbf{h} \mathrm{C} ; \mathbf{d}, \mathbf{i} 1 \mathrm{PM} ; \mathbf{e}, \mathbf{j} 2 \mathrm{PM}$. FAB thickness taking $\mathrm{FBC}$ as the anatomical reference point is represented in $\mathbf{a}-\mathbf{e}$. FAB thickness taking CEJ as the anatomical reference point is represented in figures $\mathbf{f}-\mathbf{j}$ 
Table 2 Facial alveolar bone thickness at Cl, LI, C, 1PM and 2PM at different points from FBC and CEJ

\begin{tabular}{|c|c|c|c|c|c|c|c|c|c|}
\hline Tooth type & $\mathrm{N}$ (teeth number) & Reference point & WM & SE & $95 \% \mathrm{Cl}$ & $1^{2}$ & $\mathrm{Q}_{H}(\mathrm{p}$-value $)$ & Egger (p-value) & Certainty of the evidence (grade) \\
\hline \multicolumn{10}{|c|}{$F A B$ thickness from $F B C F A B$ thickness from $F B C$} \\
\hline \multirow[t]{4}{*}{$\mathrm{Cl}$} & $14(3038)$ & $1 \mathrm{~mm}$ & 0.90 & 0.06 & $0.78-1.01$ & $99.30 \%$ & $<0.001^{* * *}$ & 0.332 & JLOW \\
\hline & $7(1369)$ & $3 \mathrm{~mm}$ & 0.98 & 0.11 & $0.77-1.19$ & $99.30 \%$ & $<0.001^{* * *}$ & - & $\oplus \oplus \oplus \bigcirc M O D E R A T E$ \\
\hline & $8(1654)$ & $5 \mathrm{~mm}$ & 0.86 & 0.08 & $0.70-1.01$ & $98.80 \%$ & $<0.001^{* * *}$ & - & $\oplus \oplus \oplus \bigcirc M O D E R A T E$ \\
\hline & $13(2721)$ & $1 \mathrm{~mm}$ & 0.89 & 0.06 & $0.77-1.00$ & $98.90 \%$ & $<0.001^{* * *}$ & 0.494 & $\oplus \oplus \oplus \bigcirc M O D E R A T E$ \\
\hline \multirow[t]{2}{*}{$\mathrm{LI}$} & $6(957)$ & $3 \mathrm{~mm}$ & 1.03 & 0.15 & $0.74-1.32$ & $99.30 \%$ & $<0.001^{* * *}$ & - & $\oplus \oplus \oplus \bigcirc$ MODERAT \\
\hline & $7(1266)$ & $5 \mathrm{~mm}$ & 0.75 & 0.11 & $0.54-0.96$ & $99.10 \%$ & $<0.001^{* * *}$ & - & $\oplus \oplus \oplus \bigcirc M O D E R A T E$ \\
\hline \multirow[t]{4}{*}{ C } & $9(1652)$ & $1 \mathrm{~mm}$ & 0.91 & 0.07 & $0.78-1.05$ & $98.70 \%$ & $<0.001^{* * *}$ & - & $\oplus \oplus \oplus \bigcirc M O D E R A T E$ \\
\hline & $6(1006)$ & $3 \mathrm{~mm}$ & 1.05 & 0.12 & $0.81-1.29$ & $98.80 \%$ & $<0.001^{* * *}$ & - & $\oplus \oplus \oplus \bigcirc M O D E R A T E$ \\
\hline & $6(1150)$ & $5 \mathrm{~mm}$ & 0.84 & 0.11 & $0.62-1.05$ & $98.80 \%$ & $<0.001^{* * *}$ & - & $\oplus \oplus \oplus \bigcirc M O D E R A T E$ \\
\hline & $4(491)$ & $1 \mathrm{~mm}$ & 1.17 & 0.1 & $0.98-1.38$ & $95.30 \%$ & $<0.001^{* * *}$ & - & $\oplus \oplus \oplus \bigcirc M O D E R A T E$ \\
\hline \multirow[t]{2}{*}{$1 P M$} & $3(461)$ & $3 \mathrm{~mm}$ & 1.26 & 0.26 & $0.76-1.76$ & $98.80 \%$ & $<0.001^{* * *}$ & - & $\oplus \oplus \bigcirc \bigcirc \mathrm{LOW}$ \\
\hline & $3(432)$ & $5 \mathrm{~mm}$ & 1.09 & 0.22 & $0.65-1.52$ & $98.50 \%$ & $<0.001^{* * *}$ & - & $\oplus \oplus \bigcirc \bigcirc \mathrm{LOW}$ \\
\hline \multirow[t]{3}{*}{$2 \mathrm{PM}$} & $4(534)$ & $1 \mathrm{~mm}$ & 1.57 & 0.07 & $1.42-1.71$ & $83.80 \%$ & $0.002^{* *}$ & - & $\oplus \oplus \oplus \bigcirc M O D E R A T E$ \\
\hline & $3(508)$ & $3 \mathrm{~mm}$ & 1.96 & 0.29 & $1.38-2.53$ & $98.30 \%$ & $0.004^{* *}$ & - & $\oplus \oplus \bigcirc \bigcirc \mathrm{LOW}$ \\
\hline & $3(508)$ & $5 \mathrm{~mm}$ & 1.82 & 0.34 & $1.15-2.49$ & $98.60 \%$ & $<0.001^{* * *}$ & - & $\oplus \oplus \bigcirc \bigcirc \mathrm{LOW}$ \\
\hline \multicolumn{10}{|c|}{ FAB thickness from CEJ } \\
\hline \multirow[t]{4}{*}{$\mathrm{Cl}$} & $7(1618)$ & $4 \mathrm{~mm}$ & 0.79 & 0.09 & $0.61-0.97$ & $99.40 \%$ & $<0.001^{* * *}$ & - & DLOW \\
\hline & $4(769)$ & $6 \mathrm{~mm}$ & 0.9 & 0.09 & $0.71-1.09$ & $99.00 \%$ & $<0.001^{* * *}$ & - & $\oplus \oplus \bigcirc \bigcirc$ LOW \\
\hline & $7(1847)$ & middle root & 0.8 & 0.05 & $0.70-0.89$ & $97.60 \%$ & $<0.001^{* * *}$ & - & $\oplus \oplus \bigcirc \bigcirc$ LOW \\
\hline & $7(1606)$ & $4 \mathrm{~mm}$ & 0.76 & 0.08 & $0.60-0.92$ & $98.80 \%$ & $<0.001^{* * *}$ & - & $\oplus \oplus \bigcirc \bigcirc \mathrm{LOW}$ \\
\hline \multirow[t]{2}{*}{$\mathrm{LI}$} & $3(423)$ & $6 \mathrm{~mm}$ & 0.79 & 0.07 & $0.65-0.93$ & $95.80 \%$ & $<0.001^{* * *}$ & - & $\oplus \oplus \oplus \bigcirc M O D E R A T E$ \\
\hline & $6(1562)$ & middle root & 0.65 & 0.04 & $0.56-0.73$ & $96.40 \%$ & $<0.001^{* * *}$ & - & $\oplus \oplus \oplus \bigcirc M O D E R A T E$ \\
\hline \multirow[t]{3}{*}{ C } & $7(1544)$ & $4 \mathrm{~mm}$ & 0.7 & 0.09 & $0.53-0.87$ & $98.70 \%$ & $<0.001^{* * *}$ & - & $\oplus \oplus \bigcirc \bigcirc \mathrm{LOW}$ \\
\hline & $3(368)$ & $6 \mathrm{~mm}$ & 0.72 & 0.09 & $0.55-0.89$ & $96.50 \%$ & $<0.001^{* * *}$ & - & $\oplus \oplus \bigcirc \bigcirc \mathrm{LOW}$ \\
\hline & $6(1555)$ & middle root & 0.65 & 0.04 & $0.58-0.73$ & $92.90 \%$ & $<0.001^{* * *}$ & - & $\oplus \oplus \oplus \bigcirc M O D E R A T E$ \\
\hline \multirow[t]{2}{*}{$1 \mathrm{PM}$} & $3(744)$ & $4 \mathrm{~mm}$ & 1.04 & 0.15 & $0.74-1.33$ & $97.90 \%$ & $<0.001^{* * *}$ & - & $\oplus \oplus \bigcirc \bigcirc \mathrm{LOW}$ \\
\hline & $2(680)$ & middle root & 0.97 & 0.24 & $0.51-1.43$ & $98.50 \%$ & $<0.001^{* * *}$ & - & $\oplus \oplus \bigcirc \bigcirc \mathrm{LOW}$ \\
\hline 2PM & $2(664)$ & $4 \mathrm{~mm}$ & 1.53 & 0.18 & $1.17-1.88$ & $95.00 \%$ & $<0.001^{* * *}$ & - & $\oplus \oplus \bigcirc \bigcirc$ LOW \\
\hline
\end{tabular}

$N$ study number, WM weighted mean, $S E$ standard error, $I^{2}$ I-squared, $C l$ confidence interval, $Q H$ Cochran's $Q^{12}$

${ }^{*} \mathrm{p}<0.05 ;{ }^{* *} \mathrm{p}<0.01 ;{ }^{* * *} \mathrm{p}<0.001$ (Strength of statistical significance)

\section{CEJ-FBC distance}

Fifteen studies (12,391 teeth) evaluated CEJ-FBC distance. The mean values were between 2.02 and $2.53 \mathrm{~mm}$ (Table 3). Considering the different age subgroups, it was a significantly greater CEJ-FBC distance in patients over 50 years of age referred to $\mathrm{CI}, \mathrm{LI}$ and $\mathrm{C}$ (Table 3). About gender, males showed a greater CEJ-FBC distance in CI $(\mathrm{p}<0.001)$. There was not enough data to assess the variability of age and gender among studies.

\section{Dehiscences and fenestrations}

Seven studies (4295 teeth) evaluated the presence of bone dehiscences and fenestrations. The prevalence of bone dehiscence was $12.3 \%$ in CI, $14.3 \%$ in LI and $20.1 \%$ in C; while the prevalence of bone fenestration was $6.4 \%$ in CI, $21.6 \%$ in LI and $23.8 \%$ in C. Concerning maxillary premolars, the available data were too limited to evaluate these parameters.

\section{Publication bias}

The test for publication bias was planned in meta-analysis with at least ten studies. The Egger's test not found hints for publications bias among meta-analyses nor for sub-group analyses assessed ( $\mathrm{p}>0.05)$. (Tables 2 and 3 ).

\section{Meta-regression analysis}

Geographical setting showed a significant effect $(\mathrm{p}<0.05)$ in most measurements as depicted in Table 4. This parameter explains a significant part of the inconsistency at all measurements for concerning LI and C, and at $5 \mathrm{~mm}$ in $\mathrm{CI}$. At $\mathrm{C}$, Asian population reported significantly thicker FAB than those from Africa and America at $1(\mathrm{R} 2=87.1 \%)$ and $3 \mathrm{~mm}(\mathrm{R} 2=63.7 \%)$ from the 


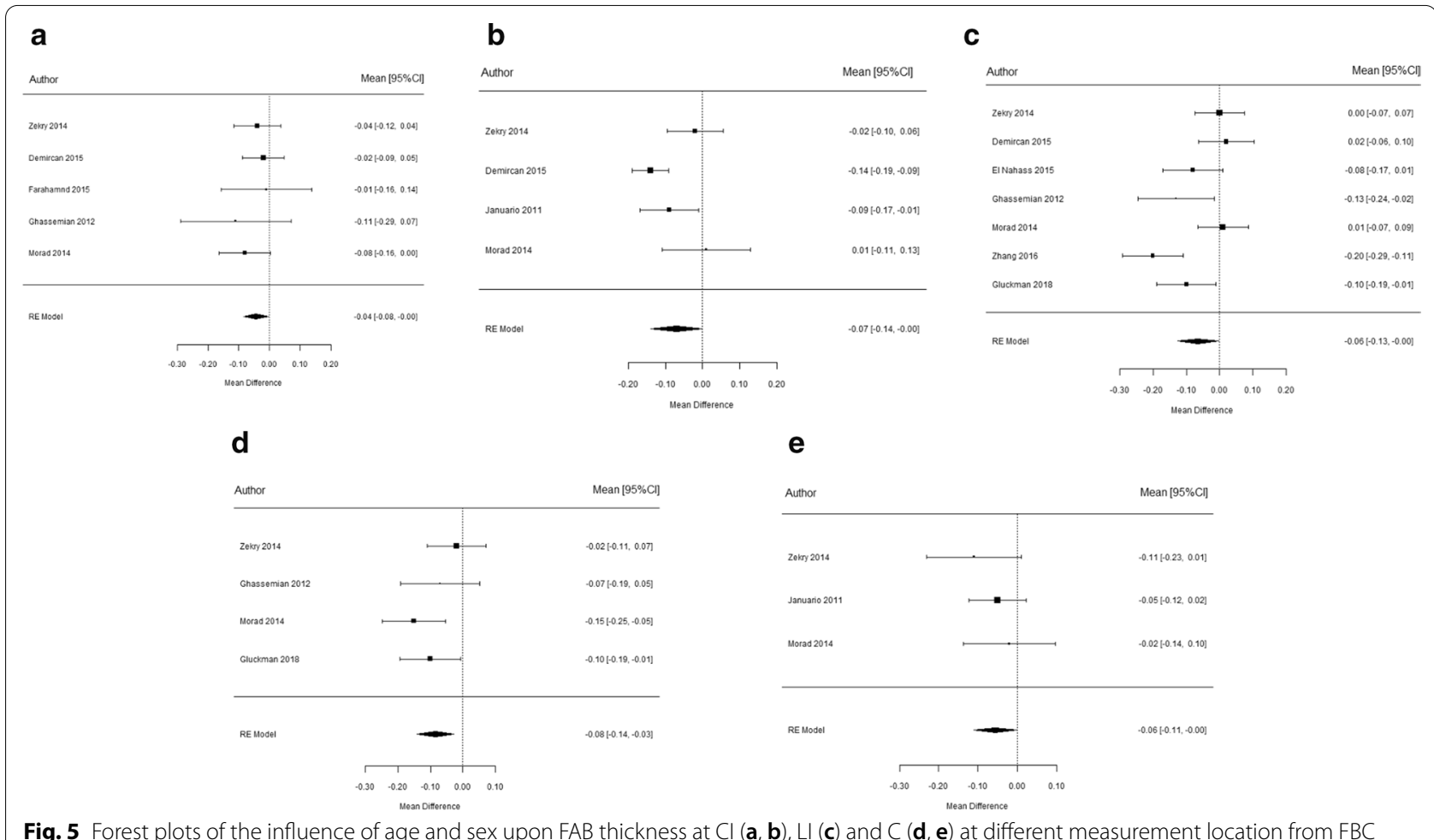

Table 3 Measurement of CEJ-FBC distance at CI, LI, C, 1PM and 2PM, and analyzed by age and gender subgroups

\begin{tabular}{|c|c|c|c|c|c|c|c|c|c|c|}
\hline Tooth type & $\mathrm{N}$ (teeth number) & Variables & WM & SE & $95 \% \mathrm{Cl}$ & $1^{2}$ & $\mathrm{Q}_{\mathrm{H}}$ (p-value) & $\begin{array}{l}\text { Egger } \\
\text { (p-value) }\end{array}$ & $z$ (p-value) & $\begin{array}{l}\text { Certainty of the } \\
\text { evidence (grade } \\
\text { ) }\end{array}$ \\
\hline \multirow[t]{3}{*}{$\mathrm{Cl}$} & $14(3024)$ & Mean distance & 2.24 & 0.12 & $2.00-2.48$ & $98.70 \%$ & $<0.001^{* * *}$ & 0.080 & $<0.001^{* * *}$ & $\oplus \oplus \oplus \bigcirc M O D E R A T E$ \\
\hline & $5(1032)$ & Sex & -0.32 & 0.11 & -0.530 .12 & $66.60 \%$ & $<0.001^{* * *}$ & - & $0.002^{* *}$ & $\oplus \oplus \oplus \bigcirc M O D E R A T E$ \\
\hline & $6(1798)$ & Age & 0.83 & 0.28 & 0.291 .38 & $98.60 \%$ & $<0.001^{* * *}$ & - & $0.003^{* *}$ & $\oplus \oplus \oplus \bigcirc M O D E R A T E$ \\
\hline \multirow[t]{3}{*}{$\mathrm{LI}$} & $13(2685)$ & Mean distance & 2.35 & 0.11 & $2.13-2.57$ & $98.40 \%$ & $<0001^{* * *}$ & 0.186 & - & $\oplus \oplus \oplus \bigcirc M O D E R A T E$ \\
\hline & $4(722)$ & Sex & -0.19 & 0.14 & -0.460 .09 & $73.10 \%$ & $0.011^{*}$ & - & 0.184 & $\oplus \oplus \bigcirc \bigcirc$ LOW \\
\hline & $6(1690)$ & Age & 0.82 & 0.23 & 0.371 .27 & $97.90 \%$ & $<0.001^{* * *}$ & - & $<0.001^{* * *}$ & $\oplus \oplus \oplus \bigcirc M O D E R A T E$ \\
\hline \multirow[t]{3}{*}{ C } & $10(2111)$ & Mean distance & 2.53 & 0.15 & $2.24-2.81$ & $98.60 \%$ & $<0.001^{* * *}$ & - & - & $\oplus \oplus \oplus \bigcirc M O D E R A T E$ \\
\hline & $3(545)$ & Sex & 0.01 & 0.32 & -0.610 .63 & $89.40 \%$ & $<0.001^{* * *}$ & - & 0.969 & $\oplus \oplus \bigcirc \bigcirc \mathrm{LOW}$ \\
\hline & $5(1513)$ & Age & 0.75 & 0.24 & 0.271 .23 & $96.60 \%$ & $<0001^{* * *}$ & - & $0.002^{* *}$ & $\oplus \oplus \oplus \bigcirc M O D E R A T E$ \\
\hline $1 \mathrm{PM}$ & $3(907)$ & Mean distance & 2.33 & 0.08 & $2.16-2.49$ & $86.70 \%$ & $<0.001^{* * *}$ & - & & $\oplus \oplus \oplus \bigcirc M O D E R A T E$ \\
\hline $2 \mathrm{PM}$ & $3(952)$ & Mean distance & 2.02 & 0.11 & $1.81-2.22$ & $93.60 \%$ & $<0.001^{* * *}$ & - & - & $\oplus \oplus \oplus \bigcirc M O D E R A T E$ \\
\hline
\end{tabular}

$N$ study number, WM weighted mean, SE standard error, $\mathrm{Cl}$ confidence interval, $\mathrm{I}^{2} \mathrm{I}$-squared, $\mathrm{QH}$ Cochran's Q

${ }^{*} p<0.05 ;{ }^{* *} p<0.01 ;{ }^{* * *} p<0.001$ (Strength of statistical significance)

FBC; also at $5 \mathrm{~mm}$ from the FBC studies from Europe showed significantly thicker FAB than those from Asia $(\mathrm{R} 2=58.71 \%)$ (Fig. 6).

The geographical setting was only significant at the middle root in $\mathrm{C}$ reporting thicker $\mathrm{FAB}$ in studies from Africa than those from Asia $(\mathrm{R} 2=53 \%)$ (Additional file 4). Moreover, this geographic setting seemed to influence on CEJ-FBC distance. On the other hand, the studies propensity for confounding- and selection-bias tended to overestimate CEJ-FBC distance (Additional file 5).

There was not an effect on the other modifiers (e.g. periodontal status, smoking, voxel size) on either $F A B$ thickness or CEJ-FBC distance. Regarding the prevalence 
Table 4 Facial alveolar bone thickness using FBC as reference point, with meta-regression of sample geographical setting at Cl, LI and C

\begin{tabular}{|c|c|c|c|c|c|c|c|c|}
\hline Tooth type & Reference point & $\mathrm{N}$ (teeth number) & Geographical setting & Beta & SE & $95 \% \mathrm{Cl}$ & $z$ (p-value) & $R^{2}$ \\
\hline \multirow[t]{10}{*}{$\mathrm{Cl}$} & $1 \mathrm{~mm}$ & $14(3038)$ & America (ref.) & & & & 0.139 & $16.00 \%$ \\
\hline & & & Asia & -0.06 & 0.14 & -0.340 .21 & 0.645 & \\
\hline & & & Europe & 0.15 & 0.16 & -0.170 .47 & 0.369 & \\
\hline & & & Africa & -0.27 & 0.18 & -0.630 .08 & 0.132 & \\
\hline & $3 \mathrm{~mm}$ & $7(1369)$ & America (ref.) & & & & 0.094 & $31.30 \%$ \\
\hline & & & Asia & -0.08 & 0.22 & -0.510 .33 & 0.682 & \\
\hline & & & Europe & 0.37 & 0.24 & -0.090 .83 & 0.118 & \\
\hline & $5 \mathrm{~mm}$ & $8(1654)$ & America (ref.) & & & & $0.037^{*}$ & $40.10 \%$ \\
\hline & & & Asia & -0.13 & 0.15 & -0.420 .16 & 0.389 & \\
\hline & & & Europe & 0.26 & 0.17 & -0.080 .59 & 0.135 & \\
\hline \multirow[t]{10}{*}{$\mathrm{LI}$} & $1 \mathrm{~mm}$ & $13(1726)$ & America (ref.) & & & & $0.049^{*}$ & $29.30 \%$ \\
\hline & & & Asia & -0.14 & 0.14 & -0.420 .14 & 0.322 & \\
\hline & & & Europe & 0.16 & 0.16 & -0.160 .47 & 0.336 & \\
\hline & & & Africa & -0.24 & 0.17 & -0.590 .11 & 0.174 & \\
\hline & $3 \mathrm{~mm}$ & $6(957)$ & Asia (ref.) & & & & $<0.001^{* * *}$ & $77.10 \%$ \\
\hline & & & Europe & 0.58 & 0.16 & 0.270 .89 & $<0.001^{* * *}$ & \\
\hline & & & America & -0.17 & 0.2 & -0.550 .23 & 0.419 & \\
\hline & $5 \mathrm{~mm}$ & $7(1336)$ & Asia (ref.) & & & & $0.004^{* *}$ & $61.70 \%$ \\
\hline & & & Europe & 0.48 & 0.16 & 0.170 .79 & $0.002^{* *}$ & \\
\hline & & & America & -0.11 & 0.2 & -0.500 .28 & 0.582 & \\
\hline \multirow[t]{10}{*}{ C } & $1 \mathrm{~mm}$ & $8(1652)$ & Asia (ref.) & & & & $<0.001^{* * *}$ & $87.10 \%$ \\
\hline & & & Europe & 0.09 & 0.06 & -0.030 .22 & 0.128 & \\
\hline & & & America & -0.44 & 0.09 & $-0.61-0.26$ & $<0.001^{* * *}$ & \\
\hline & & & Africa & -0.38 & 0.09 & $-0.55-0.2$ & $<0.001^{* * *}$ & \\
\hline & $3 \mathrm{~mm}$ & $6(1006)$ & Asia (ref.) & & & & $0.005^{* *}$ & $63.70 \%$ \\
\hline & & & Europe & 0.28 & 0.17 & -0.060 .61 & 0.105 & \\
\hline & & & America & 0.21 & 0.21 & $-0.86-0.03$ & $0.035^{*}$ & \\
\hline & $5 \mathrm{~mm}$ & $6(840)$ & Asia (ref.) & & & & $0.012^{*}$ & $58.70 \%$ \\
\hline & & & Europe & 0.33 & 0.16 & 0.010 .64 & $0.044^{*}$ & \\
\hline & & & America & -0.28 & 0.2 & -0.680 .11 & 0.159 & \\
\hline
\end{tabular}

$N$ study number, $S E$ standard error, $C l$ confidence interval, $I^{2}$ I-squared, $Q H$ Cochran's $Q, R^{2} R$-squared

${ }^{*} \mathrm{p}<0.05 ;{ }^{* *} \mathrm{p}<0.01 ;{ }^{* * *} \mathrm{p}<0.001$ (Strength of statistical significance)

of dehiscences and fenestrations, studies with controlled periodontal status and smoking habit as an inclusion criterion tended to have lower prevalences.

\section{Evidence certainty}

Evidence certainty has shown moderate quality in most analysis subsets. Still, it proves to be low-quality because of risk of bias and imprecision in others, as demonstrated by the SoF tables for primary-(Table 2) and secondary-outcomes (Table 3). Full assessment of certainty evidence by GRADE tool is presented in Additional file 6 (Table S1, S2 and S3).

\section{Discussion}

This systematic review was aimed to analyze the FAB thickness of anterior maxillary teeth measured by CBCT scans. Of 29 included studies, 17 assessed the FAB using the FBC and 12 the CEJ as anatomical references to their measurements. The included studies are observational, and most showed a moderate quality of evidence. No randomized studies were detected; due to the nature of the included data, the results should be interpreted with caution.

The main findings of this meta-analysis showed that the FAB is thin, and increases in thickness when the tooth analyzed is located in a more posterior area. Different 


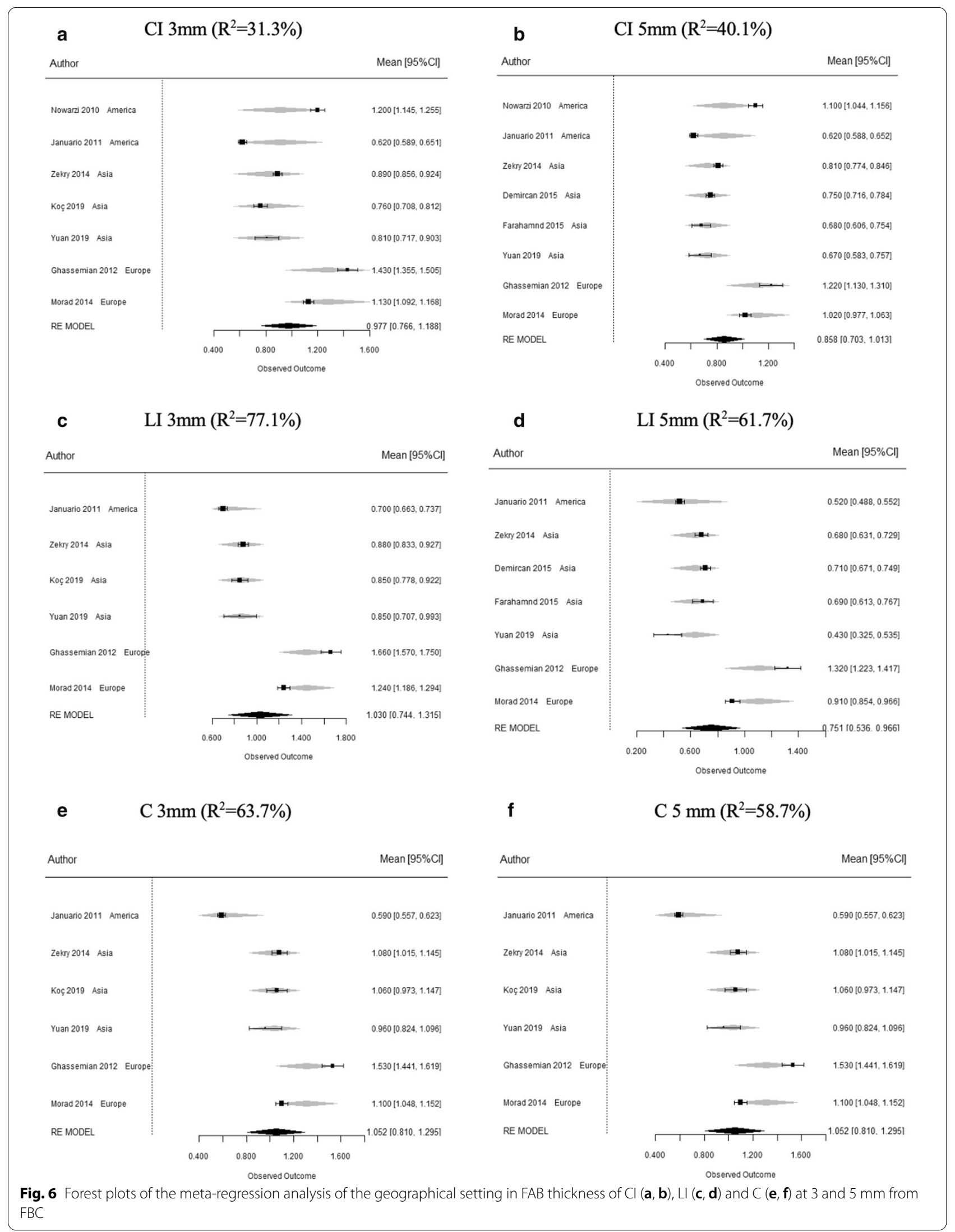


FAB values were observed depending on the anatomical reference point used. Anterior teeth (CI, LI and C) showed a mean FAB thickness $\leq 1 \mathrm{~mm}$ and maxillary premolars between 1-2 $\mathrm{mm}$. Results from studies taking CEJ as reference point showed a thinner FAB, with a more homogenous thickness pattern, when compared with those using $\mathrm{FBC}$ as the anatomical reference point (Fig. 4). The geographical setting proved to be an effect modifier that could explain up to $87 \%$ of the heterogeneity in FAB thickness measures from FBC, being Asian populations which showed the lowest FAB thickness values. Patient age, gender and gingival phenotype also influenced the results, as evidenced by the subgroups analysis. Patients over 50 years of age and females exhibited a thinner $\mathrm{FAB}$ at maxillary incisors and canines. Noteworthy to mention, the factor with the greatest influence on FAB thickness was the gingival phenotypewith clinically thicker gingival phenotypes being associated with thicker FAB phenotypes in all anterior teeth.

Regarding secondary outcomes, CEJ-FBC distance measured between 2 and $2.5 \mathrm{~mm}$ in all of the analyzed teeth. Age groups over 50 years exhibited greater distances at maxillary incisors and canines, and males also showed a trend for higher CEJ-FBC distance. The prevalence of bone dehiscence at maxillary incisors and canines oscillates around $12 \%$ to $20 \%$; while the prevalence of bone fenestration was $6.4 \%$ at $\mathrm{CI}$, and oscillates between 21 to $23 \%$ in LI and C. Nevertheless, it should be stressed that findings of the present work entailed a high heterogeneity that was sought through meta-regression analyses.

Systemic factors could also influence the CEJ-FBC distance; diabetics, hypertensive, thyroid disorders, hyperlipidemia, depression and asthma has been related to greater CEJ-FBC distance [12]. Progressive periodontal attachment loss throughout life also results in an increased CEJ-FBC distance [16]. A recent study has published an inverse relationship between CEJ-FBC distance and FAB thickness at anterior maxillary teeth [54]. Even some authors have also associated shorter CEJ-FBC distances with thicker gingival biotype [44, 45].

The scientific literature has described that FAB thickness can either be evaluated intraoperatively $1 \mathrm{~mm}$ below the alveolar bone crest after tooth extraction [11] or measured by CBCT at different apico-coronal levels before or after exodontia $[16,24,38]$. Though CBCT may optimize periodontal and implant treatment planning [55-57]; the employment of 3D technologies to obtain bidimensional measures has been the subject of intense debate in the literature provided by ex-vivo and in-vitro studies [36]. It is because some factors like patient motion reduce accuracy and reliability of linear measurements on $\mathrm{CBCT}$ images, device-specific exposure parameters, manual versus automated procedures, metallic artifacts of dental implant and bioceramic materials [36, 58, 59]. However, no significant differences were reported for bone thickness values $(-0.07 \mathrm{~mm})$ between $\mathrm{CBCT}$ and direct measurements with calipers in vivo [60]. Besides, $\mathrm{CEJ}$ anatomical reference registration is usually difficult, though its impact on bone height measurements is to be around $0.01 \mathrm{~mm}$, this is a lower difference than obtained with cusp tip $(0.1 \mathrm{~mm})$ as landmark [60]. These values are lower than the maximum errors reported for CBCTderived tooth surfaces measures in vivo $( \pm 0.2 \mathrm{~mm})$ [61] Also, this measurement variability at tooth surfaces level with $\mathrm{CBCT}$, in vivo, is not that different from those observed for FAB thickness at $\mathrm{CI}, \mathrm{LI}$ and $\mathrm{C}$. In the present work, FAB measurement standard deviations in $\mathrm{CI}$, $\mathrm{LI}$, and $\mathrm{C}$ were around $( \pm 0.2$ to $\pm 0.29 \mathrm{~mm})$ when measured from FBC; and around $( \pm 0.07$ to $\pm 0.19 \mathrm{~mm})$ when measured from the CEJ.

The voxel size is related to image resolution; values of 0.3 to $0.4 \mathrm{~mm}$ are considered suitable for planification in oral implantology [57]. The smaller the voxel size, the greater the noise, but the higher the spatial resolution [62]. The isotropic voxel size reported among the included studies was around $0.15-0.4 \mathrm{~mm}$. This covariate did not show a significant effect across the parameters assessed.

To ensure appropriate post-extraction treatment, an analysis of the $\mathrm{FAB}$ dimensions through $\mathrm{CBCT}$ scanning in the region of the tooth to be extracted can offer valuable information regarding the bone volume and the morphology of the future implant site $[19,43]$. In humans, bone modeling in single extraction sites is mainly localized to the central aspect of the $F A B$, whereas proximal aspects are well maintained by the periodontal ligaments of the adjacent teeth [9]. FAB height influences the position of the mucosal margin around teeth and implants, whereas FAB thickness exerts an influence upon the facial convexity of the alveolar process at the emerging implant crown [20]. Classically, it has been suggested that a minimum FAB thickness of $2 \mathrm{~mm}$ is an important feature for the maintenance of vertical crestal resorption following tooth extraction [63-65] - this feature rarely being found in anterior maxillary teeth. Recent studies have demonstrated that $1 \mathrm{~mm}$ of FAB could be enough to minimize alveolus postextraction morphological changes $[6,7]$. Due to the different thickness along the apico-coronal dimension of the FAB in a single tooth, postextraction morphological changes are not expected to occur in the same manner along the entire alveolus. The present review observed an increase in FAB thickness as the tooth to be analyzed is located in a more posterior area, so morphological changes after exodontia of anterior maxillary teeth with $<1 \mathrm{~mm}$ FAB thickness are expected 
to be more pronounced than those occurred at maxillary premolars with 1-2 mm FAB thickness.

A well-documented technique for minimizing postextraction morphological changes is alveolar ridge preservation, though FAB has usually resorbed unavoidably [66]. Several meta-analyses and systematic reviews have shown some benefits of alveolar ridge preservation in maintaining ridge dimensions when compared to spontaneous socket healing $[67,68]$. A recent meta-analysis could not determine a superior alveolar ridge preservation approach. However, xenogenic or allogenic materials covered with an absorbable collagen membrane were associated with the most favorable outcomes in maintaining horizontal dimensions [69]. Although benefits were observed with alveolar ridge preservation in terms of a decrease in morphological changes after tooth extraction, some degree of horizontal and vertical bone loss should still be expected [70]. Baseline FAB thickness influences the postextraction morphological changes after alveolar ridge preservation; sites exhibiting $>1 \mathrm{~mm}$ of FAB thickness underwent less vertical and horizontal bone resorption than sites presenting $<1 \mathrm{~mm}$ of FAB. The horizontal bone reduction values were $1.29 \pm 0.2 \mathrm{~mm}$ in sites with thick FAB and $3.22 \pm 0.2 \mathrm{~mm}$ in sites with thin FAB [71]. Concerning an immediate implant approach, a careful analysis of FAB integrity and thickness is mandatory [10, 72]. A recent prospective cohort study [73] of immediate implants with immediate provisionalization observed, at one year of follow-up, that bone resorption and peri-implant soft tissue recession were massive when the preoperative FAB thickness was $<0.5 \mathrm{~mm}$ compared to $0.5-1.5 \mathrm{~mm}$.

Despite the efforts like the comprehensive electronic- and complementary-literature search carried out, and the critical qualitative and quantitative synthesis of meta-evidence; the high statistical heterogeneity observed is a consequence of both clinical (e.g. sex, age, geographical setting diversity) and methodological (e.g. propensity for confounding and selection bias) heterogeneity sources among included studies due to its observational nature. Though a great extent of the observed heterogeneity was explained through meta-regression analyses, it is important to emphasize that results should be interpreted with caution because of the limitations mentioned above. The aspects mentioned above were integrated in a transparent manner using SoF tables using the GRADE approach, and using a threshold to address imprecision of the results as complementary basis. This approach allows us to reach an overall certainty of meta-analytical data, making evidence more useful, shedding light limitations that must be improved in future studies.

Some recommendations arose after this comprehensive analysis of meta-evidence: future prospective studies (comparative and randomized) should conduct according to power calculations based on the anatomical references (CEJ or FBC) and apical-coronal cut-off points. Also, it is highly recommendable to take into account the gingival phenotype, periodontal status and smoking habits feature during selection or in statistical analysis. A tentative clinical setting is the immediate implants in the anterior maxilla, allowing both preoperative $\mathrm{CBCT}$ imaging measurement of $\mathrm{FAB}$, and in-situ before implant insertion, or using non-ionizing imaging techniques like magnetic resonance. The relevancy of this topic is not only restricted to surgical procedures, but also in orthodontics and restorative dentistry.

\section{Conclusions}

Within the limitations of the present systematic review, it can be concluded that:

- Facial alveolar bone (FAB) becomes thicker as the tooth is located in a more posterior area. FAB is thinner in the first coronal and middle root locations, and thicker in-between. Incisors and canines presented a mean FAB thickness $<1 \mathrm{~mm}$ at all measurement locations. Premolars showed a mean FAB thickness between 1-2 $\mathrm{mm}$ over the whole apico-coronal dimension.

- With respect to the modifying factors in FAB thickness, females and age groups over 50 years showed significant thinner FAB at some locations of incisors and canines. However, the factor with the greatest influence on FAB at all dimensions assessed was gingival phenotype. The geographical setting proved to be an effect modifier that could explain heterogeneity in FAB thickness. Asian populations showed thinner FAB when compared with those from Europe in incisors and canines.

- The CEJ-FBC distance is quite constant at all maxillary teeth analyzed, and proved greater in individuals over 50 years of age at the incisors and canines.

\section{Abbreviations}

CBCT: Cone-beam computed tomography; FAB: Facial alveolar bone; CEJ: Cementoenamel junction; Cl: Central incisor; LI: Lateral incisor; C: Canine; 1PM: First premolar; 2PM: Second premolar. 


\section{Supplementary Information}

The online version contains supplementary material available at https://doi. org/10.1186/s12903-021-01495-2.

Additional file 1. Studies excluded by full-text assessment.

Additional file 2. Characteristics and major inferences of the selected studies.

Additional file 3. Influence of age and sex subgroups on FAB thickness at different points from $\mathrm{FBC}$ and influence of the gingival phenotype on FAB thickness at different points.

Additional file 4. Measurement of FAB thickness with CEJ as reference point analyzed by meta-regression of the geographical study setting at $\mathrm{Cl}$, LI and C.

Additional file 5. Measurement of CEJ-FBC distance analyzed by metaregression of study geographical setting $\mathrm{Cl}$, $\mathrm{LI}$ and $\mathrm{C}$.

Additional file 6. Supplementary Table S1. Assessment of the certainty of evidence by GRADE tool for FAB thickness considering FBC as anatomical reference. Supplementary Table S2. Assessment of the certainty of evidence by GRADE tool for FAB thickness considering (EJ as anatomical reference. Supplementary Table S3. Assessment of the certainty of evidence by GRADE tool for CEJ-FBC distance.

\section{Acknowledgments}

Thanks are due to Mr Juan Luis Gómez from stHalley Statistics for his contribution to the statistical analysis of the study.

\section{Authors' contributions}

JVA, DPO, MPD were involved in the design of the systematic review. JRS and DSP developed and conducted the search strategy. JRS, DSP and JVA were involved in the screening the retrieved articles for their eligibility. DSP and JRS performed the quality assessment of the selected papers. All authors (JRS, DSP, DPO, MPD, JVA) contributed to the interpretation of the findings. JRS and DSP contributed to the first drafted manuscript, with substantive revisions from all remaining authors (JVA, DPO, MPD). All authors have read and approved the final manuscript.

\section{Funding}

The authors have explicitly stated that there are no conflicts of interest in the present study. No source of funding was either required in this study.

\section{Availability of data and materials}

All data generated or analyzed during this study are included in this published article and the supplementary files for transparency.

\section{Declarations}

\section{Ethics approval and consent to participate}

Ethical approval and consent to participate are not applicable because the results are based on previously published papers.

\section{Consent for publication}

The authors have given their consent to publish.

\section{Competing interests}

The authors declare that they have no competing interests.

\section{Consent to publish}

Not applicable.

Received: 12 June 2020 Accepted: 7 March 2021

Published online: 22 March 2021

\section{References}

1. Araújo MG, Silva CO, Misawa M, Sukekava F. Alveolar socket healing: What can we learn? Periodontol. 2005;68(1):122-34. https://doi.org/10.1111/ prd.12082.

2. Araújo MG, Lindhe J. Dimensional ridge alterations following tooth extraction. An experimental study in the dog. J Clin Periodontol. 2005:32(2):212-8. https://doi.org/10.1111/j.1600-051X.2005.00642.x.

3. Chappuis V, Araújo MG, Buser D. Clinical relevance of dimensional bone and soft tissue alterations post-extraction in esthetic sites. Periodontol. 2017;73(1):73-83. https://doi.org/10.1111/prd.12167.

4. Amler $\mathrm{MH}$. The time sequence of tissue regeneration in human extraction wounds. Oral Surg Oral Med Oral Pathol. 1969;27(3):309-18.

5. Cardaropoli G, Araújo M, Lindhe J. Dynamics of bone tissue formation in tooth extraction sites. An experimental study in dogs. J Clin Periodontol. 2003;30(9):809-18.

6. Chappuis V, Engel O, Shahim K, Reyes M, Katsaros C, Buser D. Soft tissue alterations in esthetic postextraction sites: a 3-dimensional analysis. J Dent Res. 2015;94(9 Suppl):187S-193S. https://doi.org/10.1177/00220 34515592869.

7. Farmer M, Darby I. Ridge dimensional changes following single-tooth extraction in the aesthetic zone. Clin Oral Implants Res. 2014;25(2):272-7. https://doi.org/10.1111/clr.12108.

8. Vera C, De Kok IJ, Chen W, Reside G, Tyndall D, Cooper LF. Evaluation of post-implant buccal bone resorption using cone beam computed tomography: a clinical pilot study. Int J Oral Maxillofac Implants. 2012;27(5):1249-57

9. Chappuis V, Engel O, Reyes M, Shahim K, Nolte LP, Buser D. Ridge alterations post-extraction in the esthetic zone: A 3D analysis with CBCT. J Dent Res. 2013;92(12 Suppl):195S-201S. https://doi.org/10.1177/0022034513 506713.

10. Buser D, Chappuis V, Belser UC, Chen S. Implant placement post extraction in esthetic single tooth sites: When immediate, when early, when late? Periodontol. 2017;73(1):84-102. https://doi.org/10.1111/prd.12170.

11. Huynh-Ba G, Pjetursson BE, Sanz M, Cecchinato D, Ferrus J, Lindhe J, Lang NP. Analysis of the socket bone wall dimensions in the upper maxilla in relation to immediate implant placement. Clin Oral Implants Res. 2010;21(1):37-42. https://doi.org/10.1111/j.1600-0501.2009.01870.x.

12. Farahamnd A, Sarlati F, Eslami S, Ghassemian M, Youssefi N, Jafarzadeh Esfahani B. Evaluation of impacting factors on facial bone thickness in the anterior maxillary region. J Craniofac Surg. 2017;28(3):700-5. https://doi. org/10.1097/SCS.0000000000003643.

13. Zhang CY, DeBaz C, Bhandal G, Alli F, Buencamino Francisco MC, Thacker $\mathrm{HL}$, Palomo JM, Palomo L. Buccal bone thickness in the esthetic zone of postmenopausal women. Implant Dent. 2016;25(4):478-84. https://doi. org/10.1097/ID.0000000000000405.

14. Demircan S, Demircan E. Dental cone beam computed tomography analyses of the anterior maxillary bone thickness for immediate implant placement. Implant Dent. 2015;24(6):664-8. https://doi.org/10.1097/ ID.0000000000000340.

15. Morad G, Behnia H, Motamedian SR, Shahab S, Gholamin P, Khosraviani $\mathrm{K}$, Nowzari H, Khojasteh A. Thickness of labial alveolar bone overlying healthy maxillary and mandibular anterior teeth. J Craniofac Surg. 2014:25(6):1985-91. https://doi.org/10.1097/SCS.0000000000001022.

16. Zekry A, Wang R, Chau AC, Lang NP. Facial alveolar bone wall width-a cone-beam computed tomography study in Asians. Clin Oral Implants Res. 2014;25(2):194-206. https://doi.org/10.1111/clr.12096.

17. El Nahass H, Naiem S. Analysis of the dimensions of the labial bone wal in the anterior maxilla: a cone-beam computed tomography study. Clin Oral Implants Res. 2015;26(4):e57-61. https://doi.org/10.1111/clr.12332.

18. Esfahanizadeh N, Daneshparvar N, Askarpour F, Akhoundi N, Panjnoush $M$. Correlation between bone and soft tissue thickness in maxillary anterior teeth. J Dent (Tehran). 2016;13(5):302-8.

19. Ghassemian M, Nowzari H, Lajolo C, Verdugo F, Pirronti T, D'Addona A. The thickness of facial alveolar bone overlying healthy maxillary anterior teeth. J Periodontol. 2012;83(2):187-97. https://doi.org/10.1902/ jop.2011.110172. 
20. Braut V, Bornstein MM, Belser U, Buser D. Thickness of the anterior maxillary facial bone wall-a retrospective radiographic study using cone beam computed tomography. Int J Periodontics Restorative Dent. 2011;31(2):125-31.

21. Fuentes R, Flores T, Navarro P, Salamanca C, Beltrán V, Borie E. Assessment of buccal bone thickness of aesthetic maxillary region: a cone-beam computed tomography study. J Periodontal Implant Sci. 2015;45(5):1628. https://doi.org/10.5051/jpis.2015.45.5.162.

22. Kheur MG, Kantharia NR, Kheur SM, Acharya A, Le B, Sethi T. Threedimensional evaluation of alveolar bone and soft tissue dimensions of maxillary central incisors for immediate implant placement: a cone-beam computed tomography assisted analysis. Implant Dent. 2015;24(4):407_ 15. https://doi.org/10.1097/ID.0000000000000259.

23. López-Jarana P, Díaz-Castro CM, Falcão A, Falcão C, Ríos-Santos JV, Herrero-Climent M. Thickness of the buccal bone wall and root angulation in the maxilla and mandible: an approach to cone beam computed tomography. BMC Oral Health. 2018;18(1):194. https://doi.org/10.1186/ s12903-018-0652-x.

24. Nowzari H, Molayem S, Chiu CH, Rich SK. Cone beam computed tomographic measurement of maxillary central incisors to determine prevalence of facial alveolar bone width $\geq 2 \mathrm{~mm}$. Clin Implant Dent Relat Res. 2012;14(4):595-602. https://doi.org/10.1111/j.1708-8208.2010.00287 .x.

25. Wang HM, Shen JW, Yu MF, Chen XY, Jiang Q, He FM. Analysis of facial bone wall dimensions and sagittal root position in the maxillary esthetic zone: a retrospective study using cone beam computed tomography. Int J Oral Maxillofac Implants. 2014;29(5):1123-9. https://doi.org/10.11607/ jomi.3348.

26. Moher D, Liberati A, Tetzlaff J, Altman DG, PRISMA Group. Preferred reporting items for systematic reviews and meta-analyses: the PRISMA statement. Int J Surg. 2010;8(5):336-341. https://doi.org/10.1016/j. ijsu.2010.02.007.

27. Greenhalgh T, Peacock R. Effectiveness and efficiency of search methods in systematic reviews of complex evidence: audit of primary sources. BMJ. 2005;331(7524):1064-5. https://doi.org/10.1136/bmj.38636.593461.68.

28. Alpiste-illueca F. Morphology and dimensions of the dentogingival unit in the altered passive eruption. Med Oral Patol Oral Cir Bucal. 2012;17(5):e814-20. https://doi.org/10.4317/medoral.18044.

29. Chappuis V, Bornstein MM, Buser D, Belser U. Influence of implant neck design on facial bone crest dimensions in the esthetic zone analyzed by cone beam CT: a comparative study with a 5-to-9-year follow-up. Clin Oral Implants Res. 2016;27(9):1055-64. https://doi.org/10.1111/clr.12692.

30. Sterne JA, Hernán MA, Reeves BC, et al. ROBINS-l: a tool for assessing risk of bias in non-randomised studies of interventions. BMJ. 2016;355:14919. https://doi.org/10.1136/bmj.i4919.

31. Egger M, Davey Smith G, Schneider M, Minder C. Bias in meta-analysis detected by a simple, graphical test. BMJ. 1997;315(7109):629-34.

32. Veroniki AA, Jackson D, Viechtbauer W, Bender R, Bowden J, Knapp G, Kuss O, Higgins JP, Langan D, Salanti G. Methods to estimate the between-study variance and in meta-its uncertainty analysis. Res Synth Methods. 2016;7(1):55-79. https://doi.org/10.1002/jrsm.1164.

33. Chapple ILC, Mealey BL, Van Dyke TE, Bartold PM, Dommisch H, Eickholz P, Geisinger ML, Genco RJ, Glogauer M, Goldstein M, Griffin TJ, Holmstrup P, Johnson GK, Kapila Y, Lang NP, Meyle J, Murakami S, Plemons J, Romito GA, Shapira L, Tatakis DN, Teughels W, Trombelli L, Walter C, Wimmer G, Xenoudi P, Yoshie H. Periodontal health and gingival diseases and conditions on an intact and a reduced periodontium: consensus report of workgroup 1 of the 2017 World Workshop on the Classification of Periodontal and Peri-Implant Diseases and Conditions. J Clin Periodontol. 2018;45(Suppl 20):S68-77. https://doi.org/10.1111/jcpe.12940.

34. Li H, Wallin M, Barregard L, Sallsten G, Lundh T, Ohlsson C, Mellström D, Andersson EM. Smoking-induced risk of osteoporosis is partly mediated by cadmium from Tobacco Smoke: the MrOS Sweden study. J Bone Miner Res. 2020. https://doi.org/10.1002/jbmr.4014.10.1002/jbmr.4014.

35. Leite FRM, Nascimento GG, Scheutz F, López R. Effect of smoking on periodontitis: a systematic review and meta-regression. Am J Prev Med. 2018;54(6):831-41. https://doi.org/10.1016/j.amepre.2018.02.014.

36. Fokas G, Vaughn VM, Scarfe WC, Bornstein MM. Accuracy of linear measurements on CBCT images related to presurgical implant treatment planning: a systematic review. Clin Oral Implants Res. 2018;29(Suppl 16):393-415. https://doi.org/10.1111/clr.13142.
37. Gluckman H, Pontes CC, Du Toit J. Radial plane tooth position and bone wall dimensions in the anterior maxilla: a CBCT classification for immediate implant placement. J Prosthet Dent. 2018;120(1):50-6. https://doi. org/10.1016/j.prosdent.2017.09.005.

38. Januário AL, Duarte WR, Barriviera M, Mesti JC, Araújo MG, Lindhe J. Dimension of the facial bone wall in the anterior maxilla: a cone-beam computed tomography study. Clin Oral Implants Res. 2011;22(10):116871. https://doi.org/10.1111/j.1600-0501.2010.02086.x.

39. Jung $\mathrm{YH}$, Cho $\mathrm{BH}$, Hwang JJ. Analysis of the root position of the maxillary incisors in the alveolar bone using cone-beam computed tomography. Imaging Sci Dent. 2017;47(3):181-7. https://doi.org/10.5624/ isd.2017.47.3.181.

40. Koç A, Kavut İ, Uğur M. Assessment of buccal bone thickness in the anterior maxilla: a cone beam computed tomography study. Cumhur Dent J. 2019;22(1):102-7. https://doi.org/10.7126/cumudj.494676.

41. Rojo-Sanchis J, Viña-Almunia J, Peñarrocha-Oltra D, Peñarrocha-Diago M. Facial alveolar bone width at the first and second maxillary premolars in healthy patients: a cone beam computed tomography study. J Oral Implantol. 2017;43(4):261-5. https://doi.org/10.1563/aaid-joi-D-16-00195.

42. Sheerah H, Othman B, Jaafar A, Alsharif A. Alveolar bone plate measurements of maxillary anterior teeth: a retrospective Cone Beam Computed Tomography study, AlMadianh. Saudi Arabia Saudi Dent J. 2019;31(4):437-44. https://doi.org/10.1016/j.sdentj.2019.04.007.

43. Temple KE, Schoolfield J, Noujeim ME, Huynh-Ba G, Lasho DJ, Mealey BL. A cone beam computed tomography (CBCT) study of buccal plate thickness of the maxillary and mandibular posterior dentition. Clin Oral Implants Res. 2016;27(9):1072-8. https://doi.org/10.1111/clr.12688.

44. Amid R, Mirakhori M, Safi Y, Kadkhodazadeh M, Namdari M. Assessment of gingival biotype and facial hard / soft tissue dimensions in the maxillary anterior teeth region using cone beam computed tomography. Arch Oral Biol. 2017;79:1-6. https://doi.org/10.1016/j.archoralbio.2017.02.021.

45. Cook DR, Mealey BL, Verrett RG, Mills MP, Noujeim ME, Lasho DJ, Cronin RJ Jr. Relationship between clinical periodontal biotype and labial plate thickness: an in vivo study. Int J Periodontics Restorative Dent. 2011;31(4):345-54.

46. D'Silva E, Fraser D, Wang B, Barmak AB, Caton J, Tsigarida A. The association between gingival recession and buccal bone at maxillary anterior teeth. J Periodontol. 2020;91(4):484-92. https://doi.org/10.1002/ JPER.19-0375

47. Joseph G, Adnaan M, Edward M. Cone beam computed tomography assessment of the buccal bone thickness in anterior maxillary teeth: relevance to immediate implant placement. Int J Oral Maxillofac Implants. 2018;33(4):880-7. https://doi.org/10.11607/jomi.6274.

48. Ganji Kiran K, Alswilem Rayan O, Abouong Anas O, Alruwaili Abdulrahman A, Alam MK. Noninvasive evaluation of the correlation between thickness of the buccal bone and attached gingiva of maxillary premolars. J Esthet Restor Dent. 2019;31(3):240-5. https://doi.org/10.1111/ jerd.12395.

49. Khoury J, Ghosn N, Mokbel N, Naaman N. Buccal bone thickness overlying maxillary anterior teeth: a clinical and radiographic prospective human study. Implant Dent. 2016;25(4):525-31. https://doi.org/10.1097/ ID.0000000000000427.

50. Raber A, Kula K, Ghoneima A. Three-dimensional evaluation of labial alveolar bone overlying the maxillary and mandibular incisors in different skeletal classifications of malocclusion. Int Orthod. 2019;17(2):287-95. https://doi.org/10.1016/j.ortho.2019.03.011.

51. Uner DD, Izol BS, Gorus Z. Correlation between buccal and alveolar bone widths at the central incisors according to cone-beam-computed tomography. Niger J Clin Pract. 2019;22(1):79-84. https://doi.org/10.4103/ njcp.njcp_320_18.

52. Zhang S, Shi X, Liu H. Angulations of anterior teeth with reference to the alveolar bone measured by CBCT in a Chinese population. Implant Dent. 2015;24(4):397-401. https://doi.org/10.1097/ID.0000000000000291.

53. Zhou Z, Chen W, Shen M, Sun C, Li J, Chen N. Cone beam computed tomographic analyses of alveolar bone anatomy at the maxillary anterior region in Chinese adults. J Biomed Res. 2014;28(6):498-505. https://doi. org/10.7555/JBR.27.20130002.

54. Rojo-Sanchis J, Peñarrocha-Oltra D, Peñarrocha-Diago M, Zaragozí-Alonso $R$, Viña-Almunia J. Relation between the distance from the cementoenamel junction to the bone crest and the thickness of the facial bone in anterior maxillary teeth: a cross-sectional tomographic study. Med Oral 
Patol Oral Cir Bucal. 2019;24(3):e409-15. https://doi.org/10.4317/medor al.22802.

55. Nikolic-Jakoba N, Spin-Neto R, Wenzel A. Cone-beam computed tomography for detection of intrabony and furcation defects: a systematic review based on a hierarchical model for diagnostic efficacy. J Periodontol. 2016;87(6):630-44. https://doi.org/10.1902/jop.2016.150636.

56. Walter C, Schmidt JC, Dula K, Sculean A. Cone beam computed tomography (CBCT) for diagnosis and treatment planning in periodontology: a systematic review. Quintessence Int. 2016;47(1):25-37. https://doi. org/10.3290/j.qi.a34724.

57. Woelber JP, Fleiner J, Rau J, Ratka-Krüger P, Hannig C. Accuracy and usefulness of CBCT in periodontology: a systematic review of the literature. Int J Periodontics Restorative Dent. 2018;38(2):289-97. https://doi. org/10.11607/prd.2751.

58. Vanderstuyft T, Tarce M, Sanaan B, Jacobs R, de Faria VK, Quirynen M. Inaccuracy of buccal bone thickness estimation on cone-beam CT due to implant blooming: an ex-vivo study. J Clin Periodontol. 2019;46(11):113443. https://doi.org/10.1111/jcpe.13183.

59. Celikten B, Jacobs R, de Faria VK, Huang Y, Shaheen E, Nicolielo LFP, Orhan $\mathrm{K}$. Comparative evaluation of cone beam CT and micro-CT on blooming artifacts in human teeth filled with bioceramic sealers. Clin Oral Investig. 2019;23(8):3267-73. https://doi.org/10.1007/s00784-018-2748-8.

60. Li Y, Deng S, Mei L, Li J, Qi M, Su S, Li Y, Zheng W. Accuracy of alveolar bone height and thickness measurements in cone beam computed tomography: a systematic review and meta-analysis. Oral Surg Oral Med Oral Pathol Oral Radiol. 2019. https://doi.org/10.1016/j.00oo.2019.05.010.

61. Hilgenfeld T, Juerchott A, Deisenhofer UK, Weber D, Rues S, Rammelsberg P, Heiland S, Bendszus M, Schwindling FS. In vivo accuracy of tooth surface reconstruction based on CBCT and dental MRI — a clinical pilot study. Clin Oral Implants Res. 2019;30(9):920-7. https://doi.org/10.1111/ clr.13498.

62. Al-Rawi B, Hassan B, Vandenberge B, Jacobs R. Accuracy assessment of three-dimensional surface reconstructions of teeth from cone beam computed tomography scans. J Oral Rehabil. 2010;37(5):352-8. https:// doi.org/10.1111/j.1365-2842.2010.02065.x.

63. Grunder U, Gracis S, Capelli M. Influence of the 3-D bone-to-implant relationship on esthetics. Int J Periodontics Restorative Dent. 2005;25(2):113-9.

64. Spray JR, Black CG, Morris HF, Ochi S. The influence of bone thickness on facial marginal bone response: stage 1 placement through stage 2 uncovering. Ann Periodontol. 2000;5(1):119-28. https://doi.org/10.1902/ annals.2000.5.1.119.

65. Aizcorbe-Vicente J, Peñarrocha-Oltra D, Canullo L, Soto-Peñaloza D, Peñarrocha-Diago M. Influence of facial bone thickness after implant placement into the healed ridges on the remodeled facial bone and considering soft tissue recession: a systematic review. Int J Oral Maxillofac Implants. 2020;35(1):107-19. https://doi.org/10.11607/jomi.7259.

66. Bassir S, Alhareky M, Wangsrimongkol B, Jia Y, Karimbux N. Systematic review and meta-analysis of hard tissue outcomes of alveolar ridge preservation. Int J Oral Maxillofac Implants. 2018;33(5):979-94. https:// doi.org/10.11607/jomi.6399.

67. Avila-Ortiz G, Rodriguez J, Rudek I, Benavides E, Rios H, Wang HL. Effectiveness of three different alveolar ridge preservation techniques: a pilot randomized controlled trial. Int J Periodontics Restorative Dent. 2014;34(4):509-21. https://doi.org/10.11607/prd.1838.

68. Vittorini Orgeas G, Clementini M, De Risi V, de Sanctis M. Surgical techniques for alveolar socket preservation: a systematic review. Int J Oral Maxillofac Implants. 2013;28(4):1049-61. https://doi.org/10.11607/ jomi.2670.

69. Avila-Ortiz G, Chambrone L, Vignoletti F. Effect of alveolar ridge preservation interventions following tooth extraction: a systematic review and meta-analysis. J Clin Periodontol. 2019;46(Suppl 21):195-223. https://doi. org/10.1111/jcpe.13057.

70. Jambhekar S, Kernen F, Bidra AS. Clinical and histologic outcomes of socket grafting after flapless tooth extraction: a systematic review of randomized controlled clinical trials. J Prosthet Dent. 2015;113(5):371-82. https://doi.org/10.1016/j.prosdent.2014.12.009.

71. Spinato S, Galindo-Moreno P, Zaffe D, Bernardello F, Soardi CM. Is socket healing conditioned by buccal plate thickness? A clinical and histologic study 4 months after mineralized human bone allografting. Clin Oral Implants Res. 2014;25(2):e120-6. https://doi.org/10.1111/clr.12073.

72. Tonetti MS, Cortellini P, Graziani F, Cairo F, Lang NP, Abundo R, Conforti GP, Marquardt S, Rasperini G, Silvestri M, Wallkamm B, Wetzel A. Immediate versus delayed implant placement after anterior single tooth extraction: the timing randomized controlled clinical trial. J Clin Periodontol. 2017;44(2):215-24. https://doi.org/10.1111/jcpe.12666.

73. Yang X, Zhou T, Zhou N, Man Y. The thickness of labial bone affects the esthetics of immediate implant placement and provisionalization in the esthetic zone: a prospective cohort study. Clin Implant Dent Relat Res. 2019;21(3):482-91. https://doi.org/10.1111/cid.12785.

\section{Publisher's Note}

Springer Nature remains neutral with regard to jurisdictional claims in published maps and institutional affiliations.
Ready to submit your research? Choose BMC and benefit from:

- fast, convenient online submission

- thorough peer review by experienced researchers in your field

- rapid publication on acceptance

- support for research data, including large and complex data types

- gold Open Access which fosters wider collaboration and increased citations

- maximum visibility for your research: over $100 \mathrm{M}$ website views per year

At BMC, research is always in progress.

Learn more biomedcentral.com/submissions 